\title{
The Effect of Single Atom Substitution on Structure and Band Gap in Organic Semiconductors
}

Athira T. John, ${ }^{\dagger \ddagger}$ Akshaya Narayanasamy, ${ }^{\dagger \ddagger}$ Deepu George and Mahesh Hariharan ${ }^{* \ddagger}$

${ }^{\ddagger}$ School of Chemistry, Indian Institute of Science Education and Research Thiruvananthapuram, Vithura,

Thiruvananthapuram, Kerala, India 695551

\section{Supporting Information (SI) Contents}

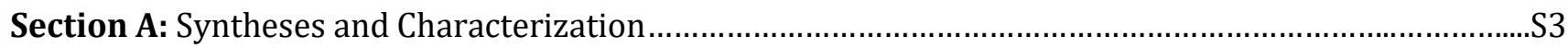

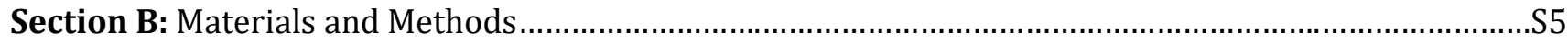

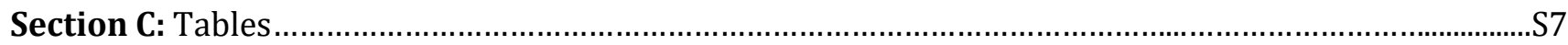

Table S1: Crystallographic data and refinement parameters for NT derivatives....................................S7

Table S2: Relative \% intermolecular interactions obtained from Hirshfeld analysis..............................S8

Table S3: Magnitudes of dipole moments for NTH, NTC, NTB and NTI ............................................. S8

Table S4: Calculated topological properties of the electron density for the intermolecular interactions in crystalline NTC .S8

Table S5: IQA interaction energies. Total non-covalent interaction energies and its components ...........S8

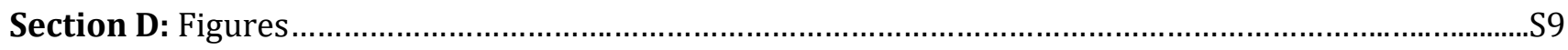

Figure S1: Crystal structure of a) NTH, b) NTC, c) NTB and d) NTI .....................................................

Figure S2: a) Interactions governing packing in NTH, NTC, NTB and NTI .............................................

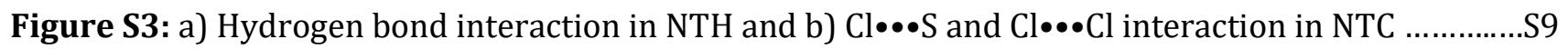

Figure S4: Role of aromatic ring stabilization in a) NTH full view, b) NTH close view and c) table showing strong and moderate aromatic interactions aromatic using analyzer component in Mercury $4.0 \ldots \ldots \ldots . . . . S 10$

Figure S5: Role of aromatic ring stabilization in a) NTC full view, b) NTC close view and c) table showing strong and moderate aromatic interactions using aromatic analyzer component in Mercury 4.0 ...........S11

Figure S6: Role of aromatic ring stabilization in a) NTB full view, b) NTB close view and c) table showing strong and moderate aromatic interactions using aromatic analyzer component in Mercury 4.0 ...........S13

Figure S7: Role of aromatic ring stabilization in a) NTI full view, b) NTI close view and c) table showing strong and moderate aromatic interactions using aromatic analyzer component in Mercury 4.0............S14 
Figure S8: QTAIM electron density map and NCI plot showing weak stabilizing interactions in NTC.

Figure S9: Intermolecular interaction energies of molecular pairs and interaction topologies of NTH.

Figure S10: Intermolecular interaction energies of molecular pairs and interaction topologies of NTC

Figure S11: Intermolecular interaction energies of molecular pairs and interaction topologies of NTB

Figure S12: Intermolecular interaction energies of molecular pairs and interaction topologies of NTI.

Figure S13: Energy framework for separate electrostatic (red), dispersion (green) and total energy (blue) for a) NT and b) NTC. The energy scale factor is 50 and the energy threshold is $5 \mathrm{~kJ} / \mathrm{mol}^{-1}$ Figure S14: Close view of conduction bands from projected density of states of (a) NTC, (b) NTB and (c)

Figure S15: ${ }^{1} \mathrm{H}$ NMR spectrum of 5-methoxynaphtho[1,2- $\left.d\right]$ thiazole in $\mathrm{CDCl}_{3}$ ..S20

Figure S16: ${ }^{13} \mathrm{C}$ NMR spectrum of 5-methoxynaphtho[1,2-d] thiazole in $\mathrm{CDCl}_{3}$ S21

Figure S17: HRMS spectrum of 5-methoxynaphtho[1,2-d] thiazole S21

Figure S18: ${ }^{1} \mathrm{H}$ NMR spectrum of 2-chloro-5-methoxynaphtho[1,2- $\left.d\right]$ thiazole in $\mathrm{CDCl}_{3}$ S22

Figure S19: ${ }^{13} \mathrm{C}$ NMR spectrum of 2-chloro-5-methoxynaphtho[1,2-d] thiazole in $\mathrm{CDCl}_{3}$ S22

Figure S20: HRMS spectrum of 2-chloro-5-methoxynaphtho[1,2-d] thiazole S23

Figure S21: ${ }^{1} \mathrm{H}$ NMR spectrum of 2-bromo-5-methoxynaphtho[1,2- $\left.d\right]$ thiazole in $\mathrm{CDCl}_{3}$ .523

Figure S22: ${ }^{13} \mathrm{C}$ NMR spectrum of 2-bromo-5-methoxynaphtho[1,2- $d$ ] thiazole in $\mathrm{CDCl}_{3}$ .524

Figure S23: HRMS spectrum of 2-bromo-5-methoxynaphtho[1,2-d] thiazole . $\mathrm{S} 24$

Figure S24: ${ }^{1} \mathrm{H}$ NMR spectrum of 2-iodo-5-methoxynaphtho[1,2- $\left.d\right]$ thiazole in $\mathrm{CDCl}_{3}$ .525

Figure S25: ${ }^{13} \mathrm{C}$ NMR spectrum of 2-iodo-5-methoxynaphtho[1,2- $\left.d\right]$ thiazole in $\mathrm{CDCl}_{3}$ S25

Figure S26: HRMS spectrum of 2-iodo-5-methoxynaphtho[1,2-d] thiazole .526

Section E: References. .526 


\section{Section A: Syntheses and Characterization}

All chemicals were obtained from commercial suppliers and used as received without further purification. All reactions were carried out in oven-dried glassware prior to use and wherever necessary, were performed under dry nitrogen in dried, anhydrous solvents using standard gastight syringes, cannula, and septa. Solvents were dried and distilled by standard laboratory purification techniques. TLC analyses were performed on recoated aluminum plates of silica gel 60 F254 plates ( $0.25 \mathrm{~mm}$, Merck) and developed TLC plates were visualized under short and long wavelength UV lamps. Flash column chromatography was performed using silica gel of 200-400 mesh employing a solvent polarity correlated with the TLC mobility observed for the substance of interest. Yields refer to chromatographically and spectroscopically homogenous substances. Melting points were obtained using a capillary melting point apparatus. ${ }^{1} \mathrm{H}$ NMR spectra was measured on a $500 \mathrm{MHz}$ Bruker avance DPX spectrometer. Internal standard used for ${ }^{1} \mathrm{H}$ NMR is tetramethyl silane (TMS). High resolution mass spectra (HRMS) were recorded on Thermo scientific $Q$ exactive mass spectrometer using Atmospheric Pressure Chemical Ionization (APCI) technique. Absorption spectra was recorded on Shimadzu UV-3600 UV-VIS-NIR spectrometer and the Kubelka-Munk transformed reflectance spectra in the crystalline state were measured in the diffuse reflectance mode. ${ }^{1}$ The diffuse reflectance spectra was used to find band gap from Tauc plot.

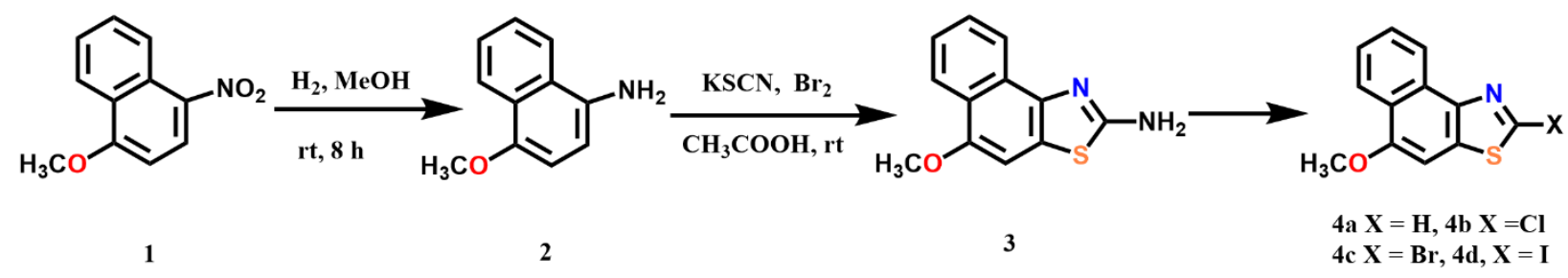

Scheme S1: Reaction scheme for the synthesis of NTH, NTC, NTB and NTI

Synthesis of compound 2: 1-methoxy-4-nitronapthalene (2.46 mmol) was dissolved in methanol and catalytic amount of Pd/C was added to the round bottom flask. The reaction mixture was purged with hydrogen and was stirred for 8 hours at room temperature. The reaction mixture was then extracted with dichloromethane. The crude mixture was used for the next reaction without further purification.

Synthesis of compound 3: Dissolved 4-ethoxynapthalen-1-amine (crude, $0.23 \mathrm{mmol}$ ) and potassium thiocyanate $(0.46 \mathrm{mmol})$ in a round bottom flask charged with glacial acetic acid and stirred for 5 minutes. Then slowly added $\mathrm{Br}_{2}$ (catalytic amount) and the reaction was stirred for 6 hours at room temperature. After confirming the full consumption of reactant, added $10 \mathrm{ml}$ of saturated sodium thiosulphate solution to quench the excess bromine in the reaction mixture. The organic compound was extracted using dichloromethane and was purified using silica gel column chromatography (petroleum ether: ethyl acetate $=3: 1$ ) to obtain compound 3 in $34 \%$ yield.

1H NMR (500 MHz, CDCl $3, \mathrm{ppm}): \delta=8.35(\mathrm{~d}, \mathrm{~J}=8 \mathrm{~Hz}, 1 \mathrm{H}), 8.19(\mathrm{~d}, \mathrm{~J}=8.5 \mathrm{~Hz}, 1 \mathrm{H}), 7.50(\mathrm{t}, \mathrm{J}=8 \mathrm{~Hz}, 1 \mathrm{H}), 7.74(\mathrm{t}$, $\mathrm{J}=8 \mathrm{~Hz}, 1 \mathrm{H}), 6.96(\mathrm{~s}, 1 \mathrm{H}), 5.13(\mathrm{~s}, 2 \mathrm{H}), 3.94(\mathrm{~s}, 3 \mathrm{H}),{ }^{13} \mathrm{C} \mathbf{N M R}\left(125 \mathrm{MHz}, \mathrm{CDCl}_{3}, \mathrm{ppm}\right): \delta=166.3,143.84,134.69$, $133.10,128.14,126.06,124.94,123.57,122.60,95.63,55.95$ 
M.p.: $225^{\circ} \mathrm{C}$

HRMS (APCI) (m/z): Calculated for $\mathrm{C}_{12} \mathrm{H}_{10} \mathrm{~N}_{2} \mathrm{OS}: 230.0514$, found: 231.0586 [M+H]

Synthesis of compound 4a (NTH): To a freshly prepared saturated solution of tertiary-butyl nitrite (1.3 mmol) in tetrahydrofuran, compound 3 dissolved in tetrahydrofuran was added dropwise using an addition funnel over one hour. The reaction mixture was heated at reflux for additional 3 hours before cooling it down to room temperature. After confirming the complete consumption of reactant, the reaction mixture was diluted with ethyl ether and washed three times with sodium thiosulphate in brine. The mixture was further separated and purified employing silica gel column chromatography using a mixture of petroleum ether and ethyl acetate (99:1) and white solid material was obtained with a yield of $38 \%$.

${ }^{1} \mathrm{H}$ NMR (500 MHz, $\left.\mathrm{CDCl}_{3}, \mathrm{ppm}\right): \delta=9.024(\mathrm{~s}, 1 \mathrm{H}), 8.81(\mathrm{~d}, \mathrm{~J}=8 \mathrm{~Hz}, 1 \mathrm{H}), 8.28(\mathrm{~d}, \mathrm{~J}=8 \mathrm{~Hz}, 1 \mathrm{H}), 7.68(\mathrm{t}, \mathrm{J}=15 \mathrm{~Hz}$, 1H), $7.56(\mathrm{t}, \mathrm{J}=15 \mathrm{~Hz}, 1 \mathrm{H}), 7.17$ (d, J = $12.5 \mathrm{~Hz}, 1 \mathrm{H}), 4.01(\mathrm{~s}, 3 \mathrm{H}),{ }^{13} \mathbf{C} \mathbf{N M R}\left(125 \mathrm{MHz}, \mathrm{CDCl}_{3}, \mathrm{ppm}\right): \delta=154.98$, $150.15,131.24,128.27,126.41,125.26,124.19,123.68,122.78,96.13,56.00$.

M.p.: $87^{\circ} \mathrm{C}$

HRMS (APCI) (m/z): Calculated for $\mathrm{C}_{12} \mathrm{H}_{9} \mathrm{NOS}: 215.0405$, found: $216.0474[\mathrm{M}+\mathrm{H}]^{+}$

Synthesis of compound $4 \mathbf{b}$ (NTC): To a round bottom flask charged with a mixture of tertiary butyl nitrite (0.97 mmol), copper (II) chloride (0.78 mmol), and acetonitrile, compound $3(0.65 \mathrm{mmol})$ was added as fractions while stirring. After complete addition, the reaction mixture was further stirred for 2 hours and stirred 1 more hour at $65{ }^{\circ} \mathrm{C}$. After confirming the complete consumption of reactant using thin layer chromatography, the crude mixture was filtered out. The filtrate was then poured into $6 \mathrm{~N} \mathrm{HCl}$ and extracted using diethyl ether. The compound $4 \mathrm{~b}$ was separated and purified from the crude residue using silica gel column chromatography (petroleum ether: ethyl acetate $=99: 1$ ) with a yield of $46 \%$.

${ }^{1} \mathrm{H}$ NMR (500 MHz, CDCl $\left.3, \mathrm{ppm}\right): \delta=8.55(\mathrm{~d}, \mathrm{~J}=8 \mathrm{~Hz}, 1 \mathrm{H}), 8.23(\mathrm{~d}, \mathrm{~J}=8 \mathrm{~Hz}, 1 \mathrm{H}), 7.60(\mathrm{~m}, \mathrm{~J}=16 \mathrm{~Hz}, 1 \mathrm{H}), 7.51(\mathrm{~m}$, $\mathrm{J}=16 \mathrm{~Hz}, 1 \mathrm{H}), 7.00(\mathrm{~s}, 1 \mathrm{H}), 3.975(\mathrm{~s}, 3 \mathrm{H}),{ }^{13} \mathrm{C} \mathbf{N M R}\left(125 \mathrm{MHz}, \mathrm{CDCl}_{3}, \mathrm{ppm}\right): \delta=153.43,147.30,140.84,132.27$, $127.29,124.97,123.98,122.45,121.58,94.73,54.89$.

M.p.: $130^{\circ} \mathrm{C}$

HRMS (APCI) (m/z): Calculated for $\mathrm{C}_{12} \mathrm{H}_{8} \mathrm{ClNOS}$ : 249.7120, found:250.0085 [M+H] ${ }^{+}$

Synthesis of compound 4c (NTB): To a solution of $3(1.3 \mathrm{mmol})$ in acetonitrile, $p$-Toluenesulfonic acid (1.7 $\mathrm{mmol}), \mathrm{CuBr}_{2}(0.02 \mathrm{mmol})$, Tetra-n-butylammonium bromide $(2.6 \mathrm{mmol})$ was added and stirred at room temperature for 4 hours. On completion of reaction, the reaction mixture was quenched by adding $15 \mathrm{ml}$ of water, washed with Sodium bicarbonate extracted with ethyl acetate. The compound 4c was obtained as a white solid after purification by means of silica gel column chromatography, ethyl acetate: petroleum ether (1:99) with a yield of $50 \%$.

${ }^{1} \mathrm{H}$ NMR (500 MHz, CDCl $\left.3, \mathrm{ppm}\right): \delta=8.59(\mathrm{~d}, \mathrm{~J}=8.5 \mathrm{~Hz}, 1 \mathrm{H}), 8.24(\mathrm{~d}, \mathrm{~J}=8.5 \mathrm{~Hz}, 1 \mathrm{H}), 7.61(\mathrm{t}, \mathrm{J}=14.5 \mathrm{~Hz}, 1 \mathrm{H}), 7.51$ $(\mathrm{t}, \mathrm{J}=15.5 \mathrm{~Hz}, 1 \mathrm{H}), 7.03$ (s, 1H), $3.981(\mathrm{~s}, 3 \mathrm{H}),{ }^{13} \mathbf{C}$ NMR (125 MHz, CDCl $\left.3, \mathrm{ppm}\right): \delta=154.47,143.39,134.74$, $133.10,128.14,126.06,124.94,123.57,122.60,95.63,55.95$.

M.p.: $143^{\circ} \mathrm{C}$

HRMS (APCI) (m/z): Calculated for $\mathrm{C}_{12} \mathrm{H}_{8} B r N O S: 294.9490$, found: 295.9554 [M+H] ${ }^{+}$

Synthesis of compound $4 \mathbf{d}$ (NTI): To a solution of $3(0.5 \mathrm{mmol})$ in acetonitrile, $p$-Toluenesulfonic acid (1.3 mmol) was added and stirred at $0{ }^{\circ} \mathrm{C}$ for 10 minutes. After complete dissolution, a saturated aqueous solution of the mixture of sodium nitrate $(0.86 \mathrm{mmol})$ and potassium iodide (1.08) was added dropwise over a period of 
15 minutes and reaction mixture was kept stirring for 5 hours. On completion of reaction, the reaction mixture was quenched by adding distilled water, further washed with Sodium bicarbonate until the $\mathrm{pH}$ reached about 9 , followed by the addition of saturated aqueous solution of sodium thiosulphate. The precipitate obtained was filtered, dried, and extracted with dichloromethane. The compound $4 \mathrm{~d}$ was obtained as a white solid after purification by means of silica gel column chromatography, ethyl acetate: petroleum ether (1:49) with a yield of $42 \%$.

${ }^{1} \mathrm{H}$ NMR (500 MHz, CDCl3, ppm): $\delta=8.63(\mathrm{~d}, \mathrm{~J}=8 \mathrm{~Hz}, 1 \mathrm{H}), 8.23(\mathrm{~d}, \mathrm{~J}=8.5 \mathrm{~Hz}, 1 \mathrm{H}), 7.60(\mathrm{~m}, \mathrm{~J}=15 \mathrm{~Hz}, 1 \mathrm{H}), 7.51$ $(\mathrm{m}, \mathrm{J}=16 \mathrm{~Hz}, 1 \mathrm{H}), 7.06$ (s, 1H), 3.97 (s, 3H), ${ }^{13} \mathrm{C}$ NMR (125 MHz, CDCl $\left.3, \mathrm{ppm}\right): \delta=154.43,145.74,136.89,127.95$, $126.04,124.76,123.55,122.55,97.94,95.36,55.92$.

M.p.: $160^{\circ} \mathrm{C}$

HRMS (APCI) (m/z): Calculated for $\mathrm{C}_{12} \mathrm{H}_{8} I N O S: 340.9371$, found: 341.9435 [M+H] ${ }^{+}$

\section{Section B: Materials and Methods}

X-ray Crystallography: High quality single crystals of NTs' were used for X-ray diffraction experiments. Single crystal was mounted using oil (Infineum V8512) on a glass fiber. All measurements were made on a CCD area detector with graphite monochromated Mo K $\alpha$ radiation. The data was collected using Bruker APEXII detector and processed using APEX2 from Bruker. The data was collected using Bruker kappa ApexII-diffractometer equipped with APEXII CCDC detector and processed using APEX2 from Bruker. The structure was solved by direct method and expanded using Fourier technique. The non-hydrogen atoms were refined anisotropically. Hydrogen atoms were included in idealized positions, but not refined. Their positions were constrained relative to their parent atom using the appropriate HFIX command in SHELX-2018. ${ }^{2}$ All programs used during the crystal structure analysis are incorporated in the WINGX software. ${ }^{3}$ The full validation of CIF and structure factor of NT crystals were performed using the checkCIF utility and found to be free of major alert levels. Three dimensional structure visualization and the exploration of the crystal packing of crystals under study were carried out using Mercury 4.0.4

Computational Methods: Single point energy and dipole moments were calculated at the $\omega B$ 97XD/Def2-TZVP level of theory. ${ }^{5}$ All these computations were performed using the Gaussian 09 and 16 suite. ${ }^{6}$ Band structure and projected density of states calculation was performed within local density approximation using Quantum Espresso package.

Quantum Theory of Atoms in Molecules (QTAIM): ${ }^{7}$ The wave function generation for NT derivatives were carried out at $\omega$ B97XD/Def2-TZVP level of theory using Gaussian09 and Gaussian16. Quantum theory of atoms in molecules (QTAIM) analyses helps to understand the description of interatomic interaction in the single crystal X-ray structure. A bond is defined along the bond line between two nuclei, called a bond path, along which electron density is concentrated. The $(3,-1)$ bond critical point (BCP) is a point along the bond path at the interatomic surface, where the shared electron density reaches a minimum. $(3,+1)$ ring critical point (RCP) and $(3,+3)$ cage critical point (CCP) represents critical points in the ring and cage respectively where the electron density is minimum. The physical characteristics of the critical points [the electron density at BCP, RCP and CCP, $\rho(r)$, and its Laplacian, $\nabla^{2} \rho(r)$ reveal the approximate measure of the amount of electron density built up in the bonding region and as such could be taken as characteristic of the bond. When $\nabla^{2} \rho(r)<0$ and is large in magnitude, $\rho(r)$ is also large which means that there is a concentration of electronic charge in the internuclear 
region. This is also an indication of a sharing of electronic charge between both nuclei that defines the covalent (polar) bond. When $\nabla^{2} \rho(r)>0$ there is a depletion of electronic charge in the internuclear region and it indicates a closed shell interaction. Using the AIMAll software package, the electron density was integrated over atomic basins according to the quantum theory of atoms in molecules using PROAIM, and thus the BCP, RCP, CCP data and the molecular graphs were obtained.

Hirshfeld Analysis: ${ }^{8}$ Important intermolecular interactions within the structure of NT derivatives were identified through Hirshfeld surface analysis using CrystalExplorer17.9,10 The Hirshfeld surface is defined as a set of points in 3D space where the ratio of promolecule and procrystal electron densities is equal to 0.5 . The exploration of intermolecular contacts is provided by mapping normalized contact distances $\left(\mathrm{d}_{\text {norm}}\right)$, which is a function of a closest distance from the point to the nuclei interior $\left(\mathrm{d}_{\mathrm{i}}\right)$ and exterior $\left(\mathrm{d}_{\mathrm{e}}\right)$ to the surface as well as on the van der Waals radii $\left(\mathrm{r}_{\mathrm{vdw}}\right)$. 2D fingerprint plots derived from the Hirshfeld surface analyses, by plotting the fraction of points on the surface as the function of $d_{i}$ and $d_{e}$, provides a visual summary of intermolecular contacts within the crystal.

Non-Covalent Interaction: ${ }^{11} \mathrm{NCI}$ analysis employs an index based on electron density and its derivatives to identify noncovalent interactions. A two-dimensional plot of reduced electron density (s) against electron density $(\rho)$ and the critical points are associated with the troughs appearing in the plot. Reduced electron density is given by:

$$
S=\frac{1|\nabla \rho|}{2\left(3 \pi^{2}\right)^{1 / 3} \rho^{4 / 3}}
$$

Noncovalent interactions occur in the real space points where these troughs appear. The sign of second derivative of $\rho\left(\nabla^{2} \rho\right)$ is analyzed to distinguish attractive and repulsive interactions. The noncovalent interaction regions are represented in the plot as discs with color ranging from blue (attractive) to red (repulsive) as in the VIBGYOR spectrum.

Interacting Quantum Atoms (IQA):12 IQA approach was done on NT derivatives using AIMALL software to understand the nature of intermolecular interactions. Hamiltonian is partitioned into physical atomic and interatomic contributions. The energy decomposition computed using partitioned Hamiltonian is consistent with the topological method of quantum theory of atoms in molecules contribution values determine the nature of intermolecular or intramolecular interactions.

The total interatomic energy $\left(E_{t}^{A B}\right)$ is the summation of interparticle [electron (e) and nucleus $(\mathrm{n})$ ] interaction energies, which is given by

$$
E_{t}^{A B}=E_{n n}^{A B}+E_{e n}^{A B}+E_{n e}^{A B}+E_{e e}^{A B}
$$

Where the electron-electron interaction is the summation of exchange $\left(E_{X}^{A B}\right)$, correlation $\left(E_{C}^{A B}\right)$ and coulomb $\left(E_{\text {Coul }}^{A B}\right)$ potentials

$$
E_{e e}^{A B}=E_{X}^{A B}+E_{C}^{A B}+E_{c o u l}^{A B}
$$

Now, as per IQA, the classical component $\left(E_{c l}^{A B}\right)$ is the union of all the electrostatic terms

$$
E_{c l}^{A B}=E_{n n}^{A B}+E_{\text {en }}^{A B}+E_{n e}^{A B}+E_{C o u l}^{A B}
$$


and the exchange-correlation component consists of all the quantum terms

$$
E_{X C}^{A B}=E_{X}^{A B}+E_{C}^{A B}
$$

Thus, total interatomic interaction energy is decomposed into classical and quantum terms separately

$$
E_{t}^{A B}=E_{c l}^{A B}+E_{X C}^{A B}
$$

\section{Section c: Tables}

\begin{tabular}{|c|c|c|c|c|}
\hline Parameters & NTH & NTC & NTB & NTI \\
\hline Formula & $\mathrm{C}_{12} \mathrm{H}_{9} \mathrm{NOS}$ & $\mathrm{C}_{12} \mathrm{H}_{8} \mathrm{ClNOS}$ & $\mathrm{C}_{12} \mathrm{H}_{8} \mathrm{BrNOS}$ & $\mathrm{C}_{12} \mathrm{H}_{8} \mathrm{INOS}$ \\
\hline Formula weight & 215.26 & 249.70 & 294.16 & 341.15 \\
\hline Color & Colorless & Colorless & Colorless & Colorless \\
\hline Crystal system & Monoclinic & Monoclinic & Monoclinic & Monoclinic \\
\hline Space group, Z & $P 21 / \mathrm{n}, 4$ & $P n, 4$ & $P 21 / \mathrm{n}, 4$ & $P 21 / \mathrm{n}, 4$ \\
\hline a $(\AA)$ & 4.068 & 10.517 & 7.7447 & 7.8661 \\
\hline $\mathrm{b}(\AA)$ & 14.469 & 3.9053 & 13.387 & 13.4536 \\
\hline c $(\AA)$ & 17.030 & 26.075 & 10.8438 & 10.9374 \\
\hline$\alpha, \operatorname{deg}$ & 90 & 90 & 90 & 90 \\
\hline$\beta, \operatorname{deg}$ & 94.047 & 93.255 & 95.757 & 95.314 \\
\hline$\gamma, \operatorname{deg}$ & 90 & 90 & 90 & 90 \\
\hline Volume, $\AA^{3}$ & 1000.1 & 1069.2 & 1118.6 & 1152.50 \\
\hline $\mathrm{R}$ factor & 4.3 & 5.62 & 4.22 & 1.83 \\
\hline Temp, K & 296 & 296 & 296 & 296 \\
\hline $\mathrm{d}_{\text {calculated }}\left(\mathrm{mg} / \mathrm{m}^{3}\right)$ & 1.430 & 1.551 & 1.747 & 1.966 \\
\hline No. of reflections collected & 11663 & 14351 & 15748 & 14736 \\
\hline No. of unique reflections & 1756 & 5020 & 1971 & 2030 \\
\hline $2 \theta_{\max }, \operatorname{deg}$ & 25 & 28.072 & 24.997 & 24.997 \\
\hline No. of parameters & 137 & 291 & 146 & 145 \\
\hline R1, wR2, $(\mathrm{l}>2 \mathrm{~s}(\mathrm{l}))$ & $0.0433,0.0920$ & $0.0562,0.1023$ & $0.0422,0.0742$ & $\begin{array}{l}0.0183 \\
0.0456\end{array}$ \\
\hline R1, wR2 (all data) & $0.0817,0.1097$ & $0.1126,0.1199$ & $0.0850,0.0892$ & $\begin{array}{l}0.0206 \\
0.0474\end{array}$ \\
\hline
\end{tabular}

Table S1. Crystallographic data and refinement process for NT derivatives. 
Table S2. Relative \% intermolecular interactions obtained from Hirshfeld analysis.

\begin{tabular}{|c|c|c|c|c|c|c|c|c|}
\hline Interaction & $\mathrm{C} \cdots \mathrm{C}$ & $\mathrm{C} \cdots \mathrm{H}$ & $\mathrm{S} \cdots \mathrm{H}$ & $\mathrm{N} \cdots \mathrm{H}$ & $\mathrm{X} \cdots \mathrm{S}$ & $\mathrm{H} \cdots \mathrm{X}$ & $\mathrm{H} \cdots \mathrm{H}$ & $\rho=[(\% \mathrm{C} \cdots \mathrm{H}) /(\% \mathrm{C} \cdots \mathrm{C})]$ \\
\hline NTH & 11.7 & 14.5 & 13.3 & 7 & 0.0 & 0.0 & 42.2 & 1.2 \\
\hline NTC & 11.1 & 11.7 & 12.2 & 6.2 & 2.6 & 14.8 & 28.7 & 1.0 \\
\hline NTB & 7.7 & 10.5 & 10 & 5.1 & 0.1 & 19.3 & 27.4 & 1.3 \\
\hline NTI & 7.6 & 10.7 & 10.1 & 5.2 & 0.2 & 20.9 & 25.8 & 1.4 \\
\hline
\end{tabular}

Table S3. Magnitudes of dipole moments (Debye) for monomer and antiparallel stacked dimers in the crystal packing of NTs.

\begin{tabular}{|c|c|c|}
\hline NT derivatives & Monomer & Anti-parallel dimer \\
\hline NTH & 2.72 & - \\
\hline NTC & 3.69 & - \\
\hline NTB & 3.65 & 0.00 \\
\hline NTI & 3.41 & 0.00 \\
\hline
\end{tabular}

Table S4. Calculated topological properties of electron density function for the intermolecular interactions in crystalline NTC.

\begin{tabular}{|c|c|c|c|c|c|}
\hline & & Interactions & $\mathrm{d}, \AA$ & $\rho(r), e^{-3}$ & $\nabla^{2} \rho(\mathrm{r}), \mathrm{e} \AA^{-5}$ \\
\hline 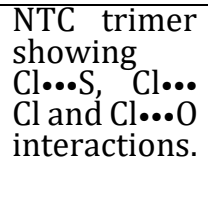 & $\begin{array}{l}\text { Bond } \\
\text { critical } \\
\text { points } \\
\text { (BCPs) }\end{array}$ & $\begin{array}{l}\mathrm{Cl} 21 \bullet \bullet \mathrm{S} 48 \\
\mathrm{Cl} 21 \bullet \bullet \mathrm{Cl} 45 \\
\mathrm{O} 71 \bullet \bullet \mathrm{Cl} 45\end{array}$ & $\begin{array}{l}3.553 \\
3.770 \\
3.136\end{array}$ & $\begin{array}{l}0.005478 \\
0.004427 \\
0.007468\end{array}$ & $\begin{array}{l}0.020702 \\
0.014898 \\
0.031625\end{array}$ \\
\hline
\end{tabular}

Table S5. IQA interaction energies. Total noncovalent interaction energies and its components of NTC are shown. Energies are given in kcal/mol.

\begin{tabular}{|c|c|c|c|c|}
\hline & Interactions & $E_{\mathrm{t}}$ & $E_{\mathrm{xc}}$ & $E_{\mathrm{cl}}$ \\
\hline \multirow{3}{*}{ NTC trimer } & $\mathrm{Cl} 21 \bullet \cdot \mathrm{S} 48$ & -8.26 & -4.96 & -3.30 \\
\cline { 2 - 5 } & $\mathrm{Cl} 21 \bullet \cdot \mathrm{Cl} 45$ & -0.41 & 3.08 & -3.49 \\
\cline { 2 - 5 } & $071 \cdots \mathrm{Cl} 45$ & 10.53 & 15.63 & -5.09 \\
\hline
\end{tabular}




\section{Section D: Figures}

a)

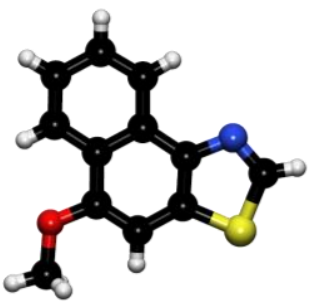

b)

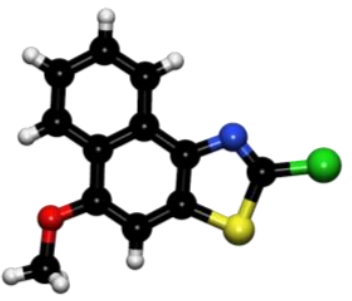

c)

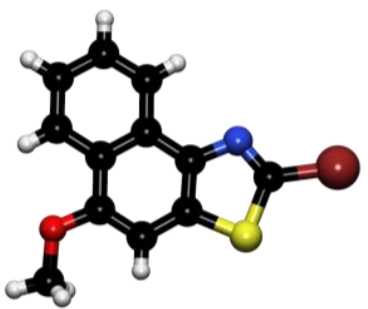

d)

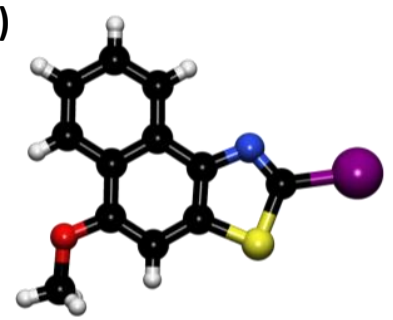

Figure S1: Crystal structure of a) NTH, b) NTC, c) NTB and d) of NTI.

a)

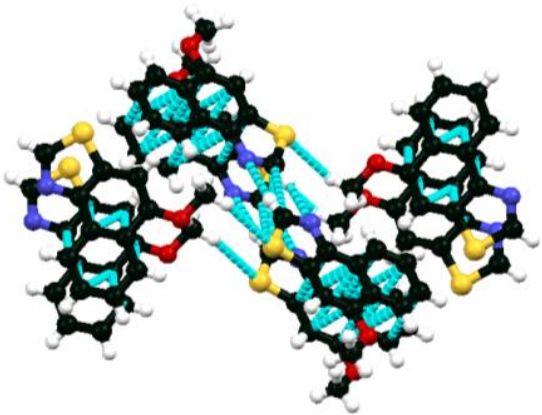

c)

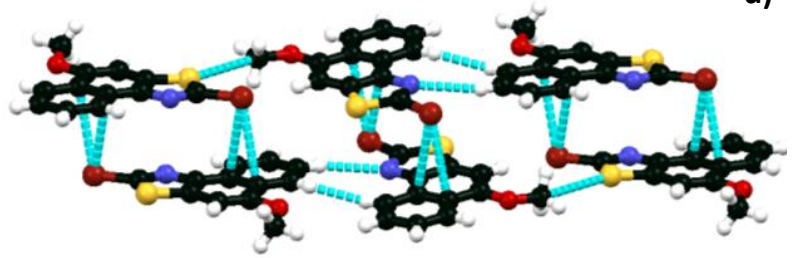

b)

d)
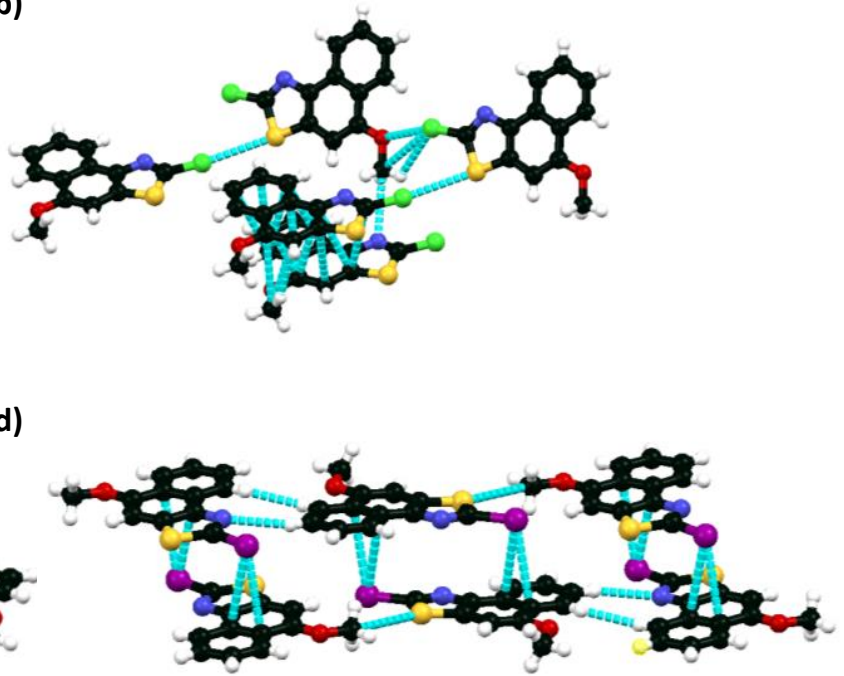

Figure S2: Interactions governing packing in a) NTH, b) NTC, c) NTB and d) NTI.

a)

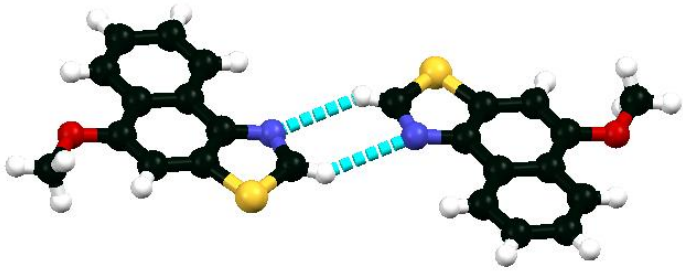

b)

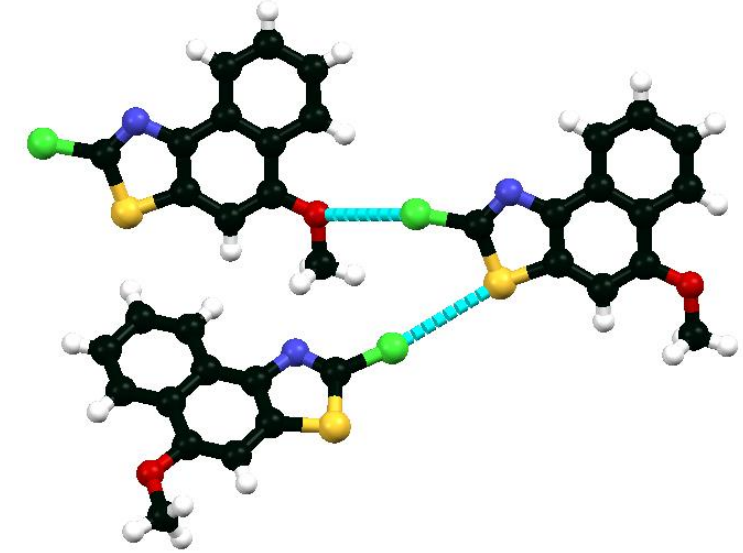

Figure S3: a) Hydrogen bond interaction in NTH and b) Cl...S and Cl $\cdots$ Cl interaction in NTC. 
a)

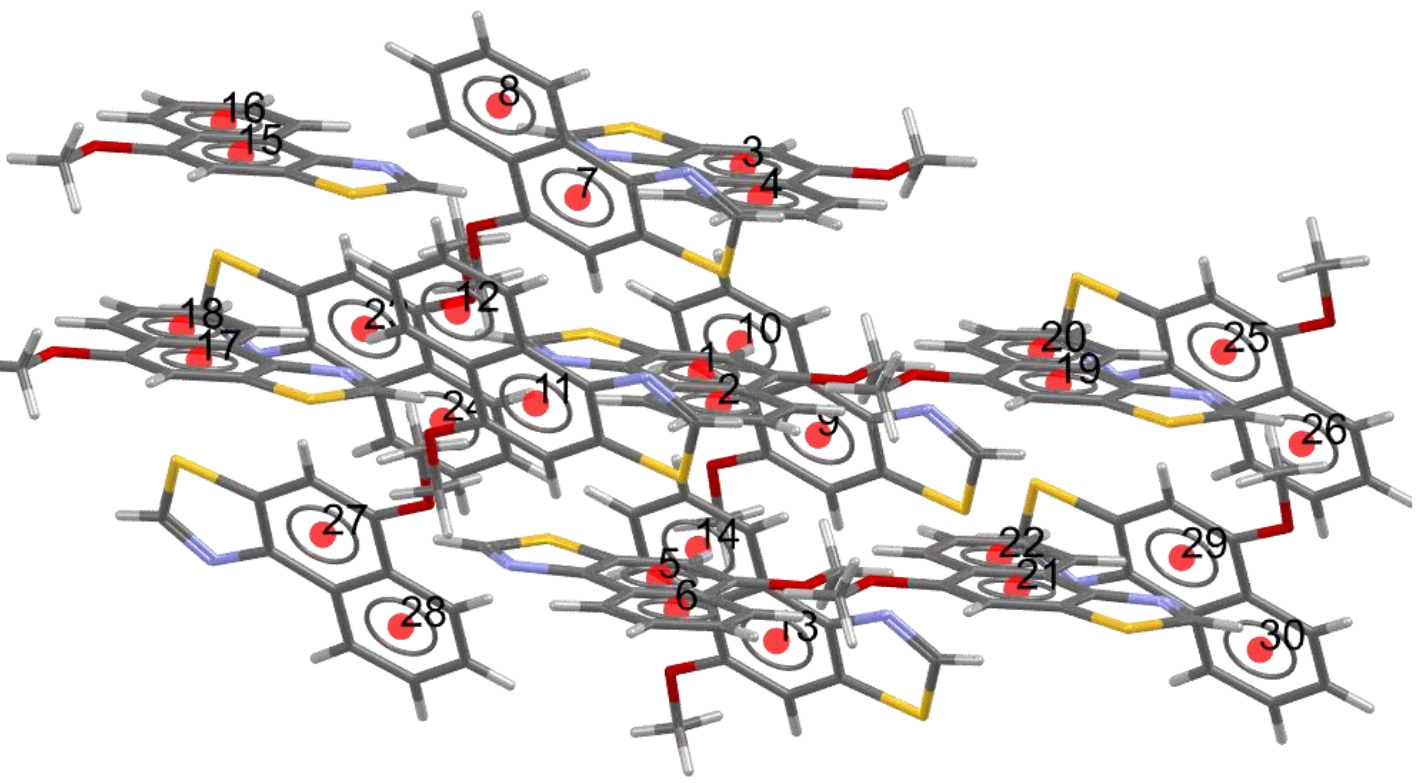

b)

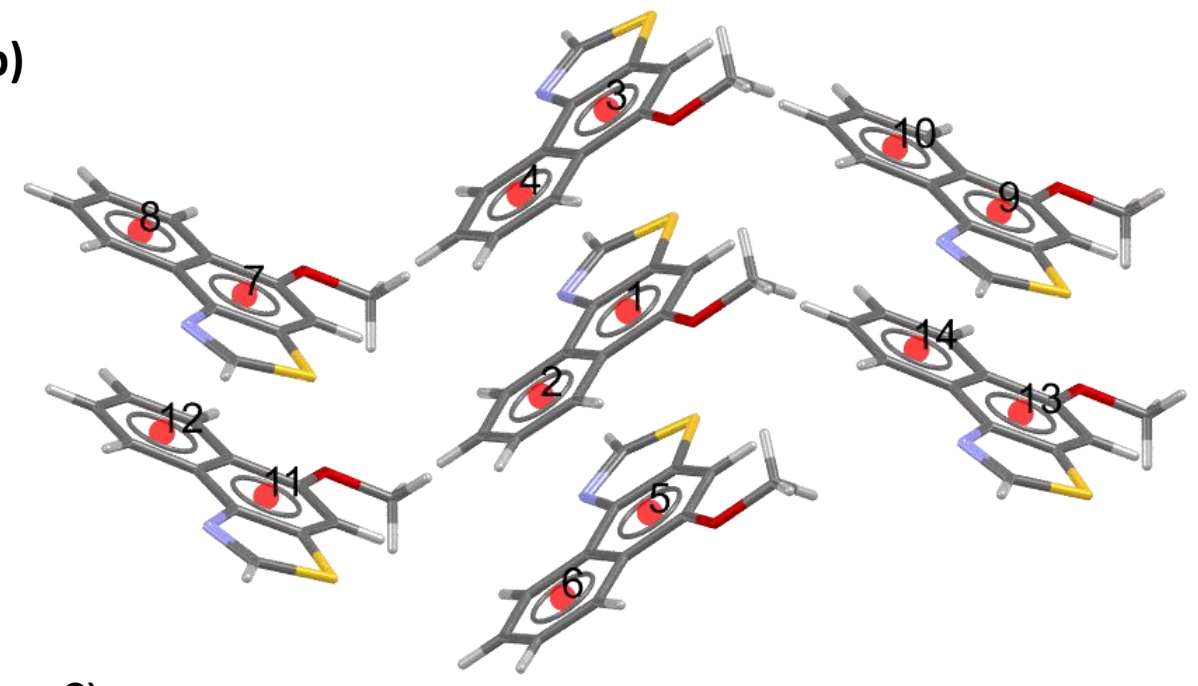

C)

\begin{tabular}{|c|c|c|c|c|}
\hline Centroid 1 & Centroid 2 & Distance & Score & Profile \\
\hline 1 & 3 & 4.07 & 9.5 & Strong \\
\hline 1 & 5 & 4.07 & 9.5 & Strong \\
\hline 2 & 4 & 4.07 & 9.4 & Strong \\
\hline 2 & 6 & 4.07 & 9.4 & Strong \\
\hline 1 & 4 & 3.68 & 8.6 & Strong \\
\hline 2 & 5 & 3.68 & 8.6 & Strong \\
\hline 1 & 6 & 5.62 & 5.4 & Moderate \\
\hline 2 & 3 & 5.62 & 5.4 & Moderate \\
\hline & & & & \\
\hline
\end{tabular}




\begin{tabular}{|l|l|l|l|l|}
\hline 1 & 10 & 6.01 & 5.3 & Moderate \\
\hline 1 & 14 & 5.91 & 5.3 & Moderate \\
\hline 2 & 7 & 6.01 & 5.3 & Moderate \\
\hline 2 & 11 & 5.91 & 5.3 & Moderate \\
\hline
\end{tabular}

Figure S4: Role of aromatic ring stabilization in a) NTH full view, b) NTH close view and c) table showing strong and moderate aromatic interactions using aromatic analyzer component in Mercury 4.0.

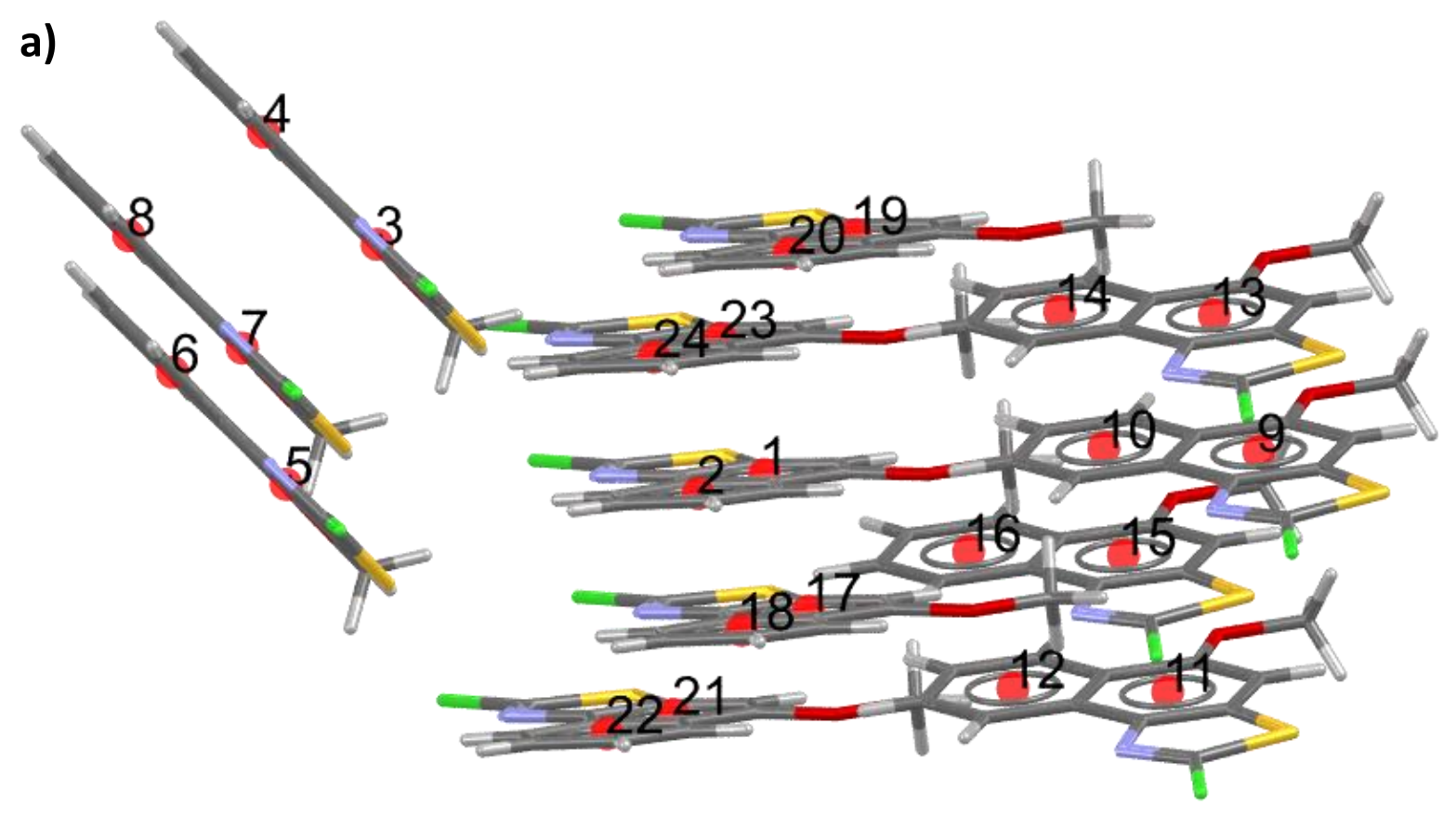

b)

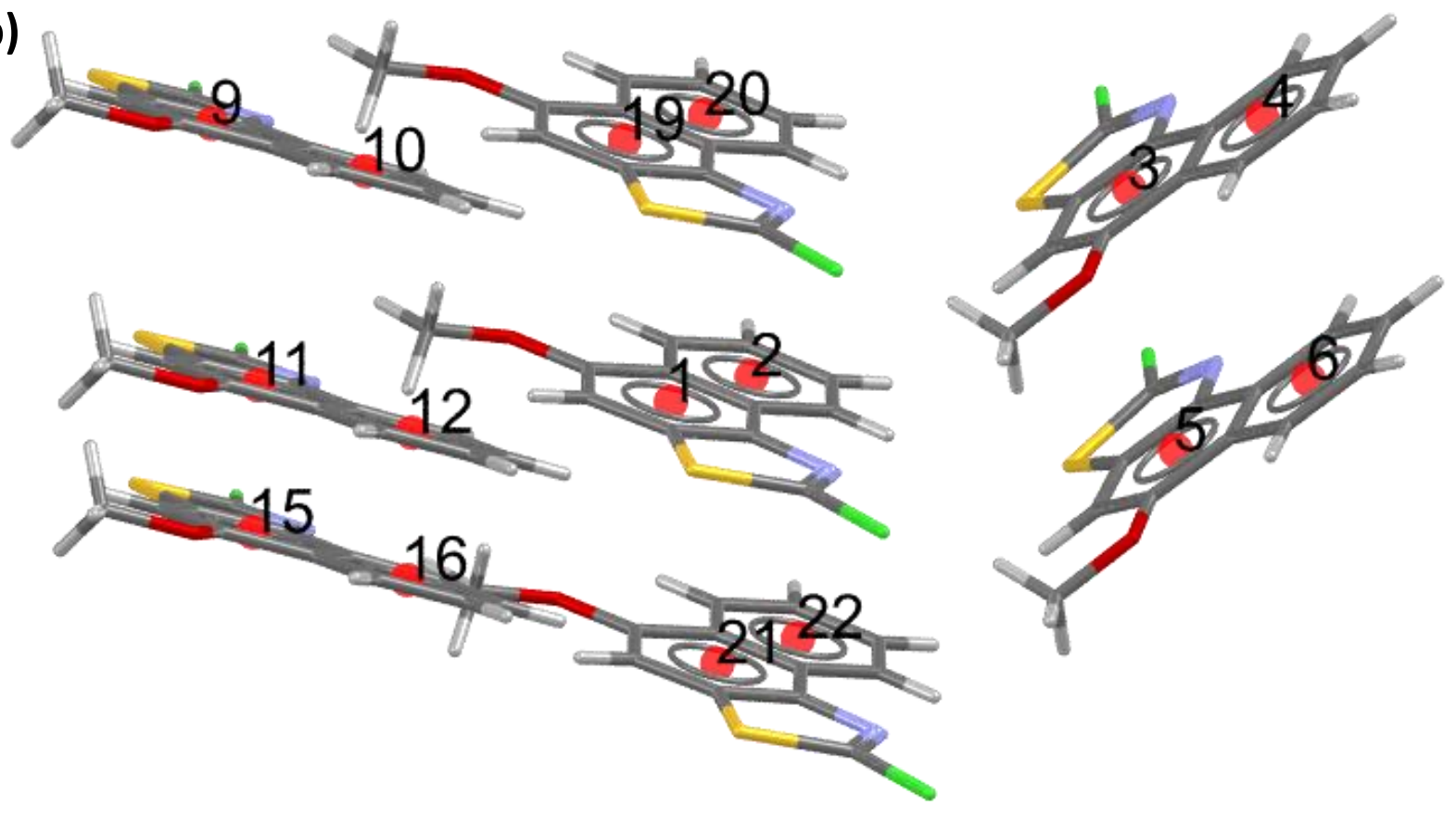


C)

\begin{tabular}{|c|c|c|c|c|}
\hline Centroid 1 & Centroid 2 & Distance & Score & Profile \\
\hline 1 & 19 & 3.91 & 9.8 & Strong \\
\hline 1 & 21 & 3.91 & 9.8 & Strong \\
\hline 2 & 20 & 3.91 & 9.8 & Strong \\
\hline 2 & 22 & 3.91 & 9.8 & Strong \\
\hline 1 & 20 & 4.37 & 8.5 & Strong \\
\hline 2 & 21 & 4.37 & 8.5 & Strong \\
\hline 1 & 22 & 4.81 & 7.4 & Strong \\
\hline 2 & 19 & 4.81 & 7.4 & Strong \\
\hline 2 & 12 & 6.08 & 5.8 & Moderate \\
\hline 2 & 3 & 6.14 & 5 & Moderate \\
\hline 2 & 5 & 6.19 & 4.8 & Moderate \\
\hline 1 & 16 & 6.53 & 4.3 & Moderate \\
\hline 1 & 12 & 6.77 & 3.5 & Moderate \\
\hline 2 & 10 & 6.87 & 3.2 & Moderate \\
\hline
\end{tabular}

Figure S5: Role of aromatic ring stabilization in a) NTC full view, b) NTC close view and c) table showing strong and moderate aromatic interactions using aromatic analyzer component in Mercury 4.0.

\section{a)}

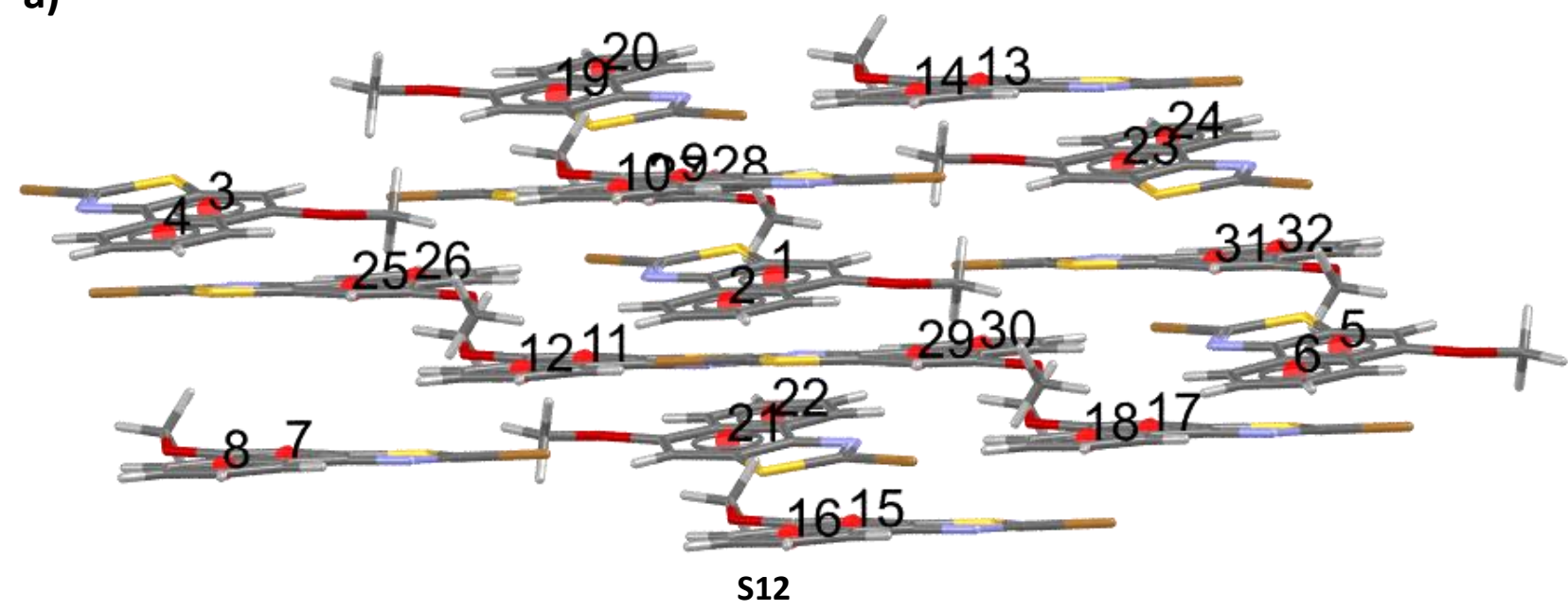


b)

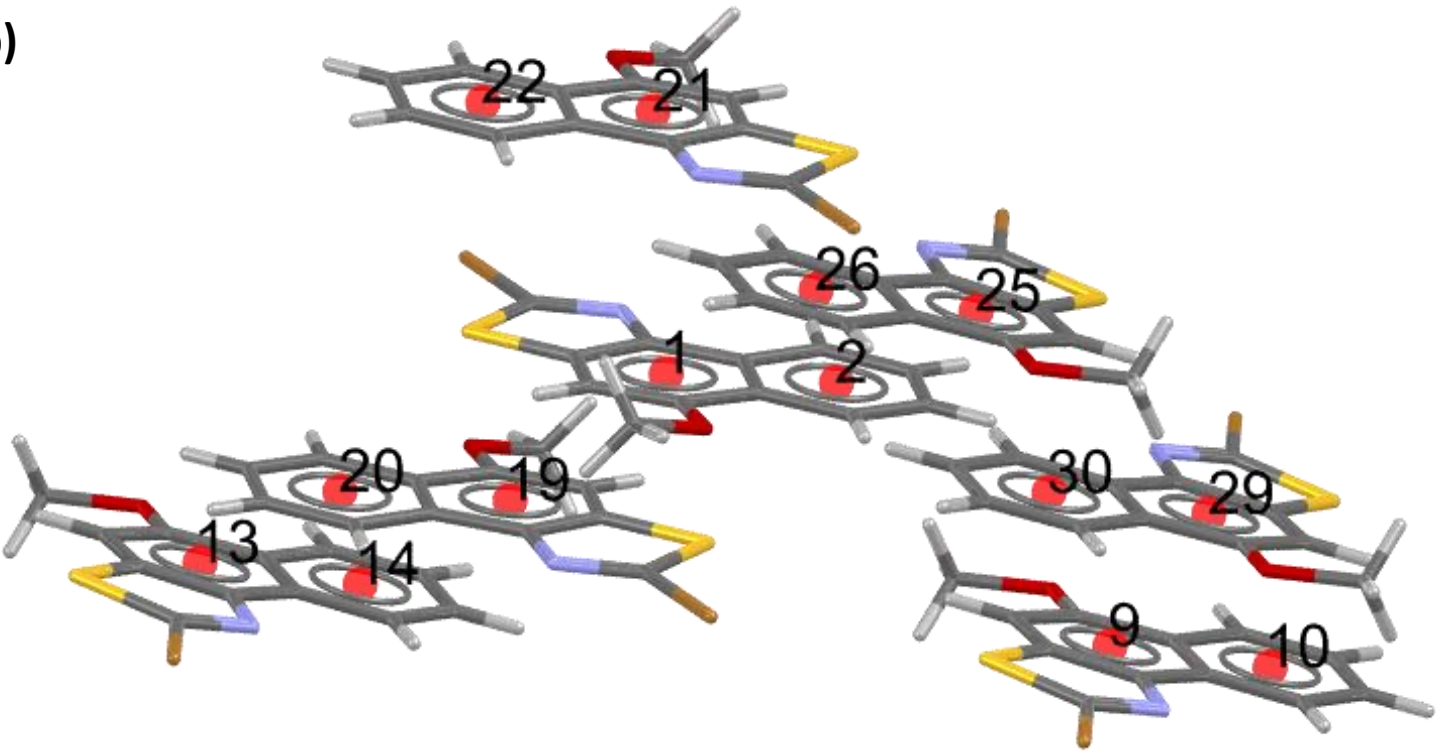

C)

\begin{tabular}{|c|c|c|c|c|}
\hline Centroid 1 & Centroid 2 & Distance & Score & Profile \\
\hline 1 & 21 & 3.71 & 10 & Strong \\
\hline 1 & 22 & 4.61 & 8.4 & Strong \\
\hline 2 & 21 & 4.61 & 8.4 & Strong \\
\hline 1 & 14 & 5.43 & 7.1 & Strong \\
\hline 2 & 9 & 5.43 & 7.1 & Strong \\
\hline 1 & 19 & 6.06 & 4.5 & Moderate \\
\hline 2 & 22 & 6.38 & 3.9 & Moderate \\
\hline 2 & 26 & 6.49 & 3.1 & Moderate \\
\hline 2 & 30 & 6.49 & 3.1 & Moderate \\
\hline
\end{tabular}

Figure S6: Role of aromatic ring stabilization in a) NTB full view, b) NTB close view and c) table showing strong and moderate aromatic interactions using aromatic analyzer component in Mercury 4.0. 
a)

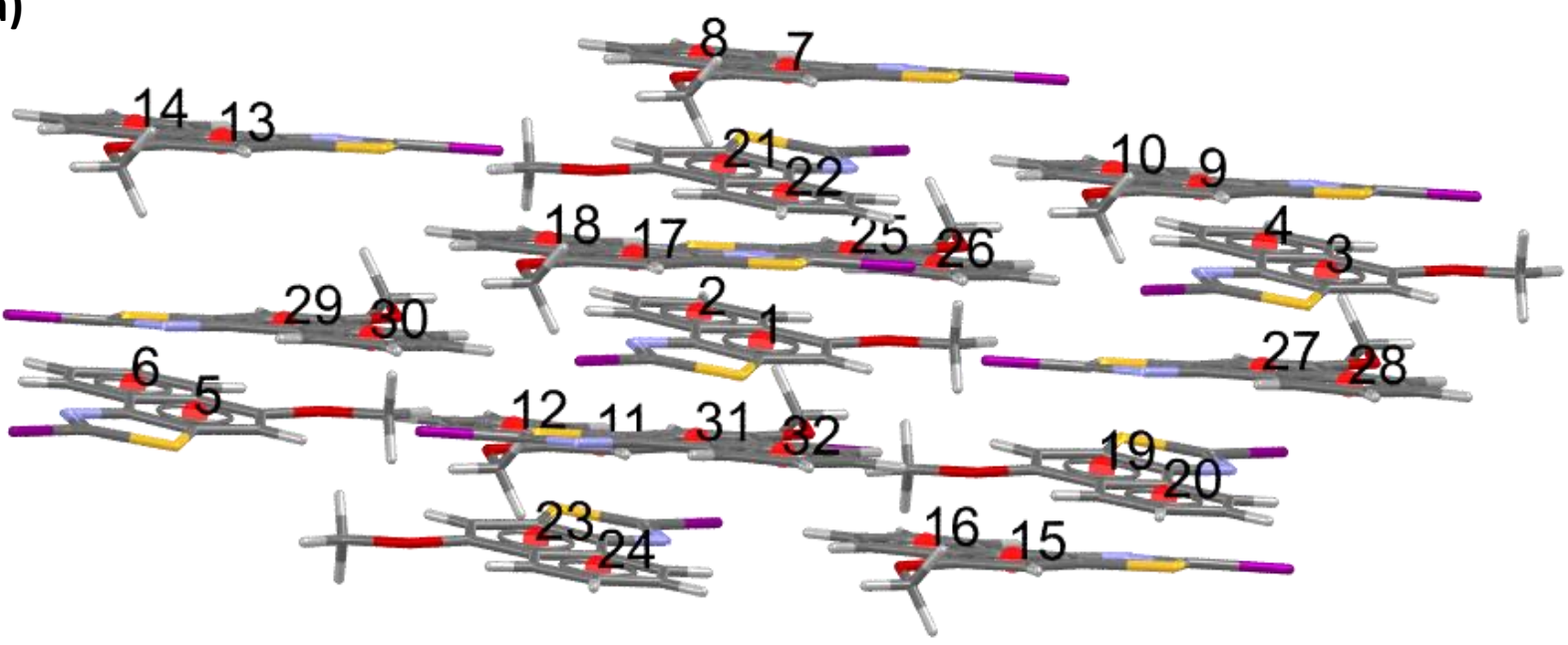

b)
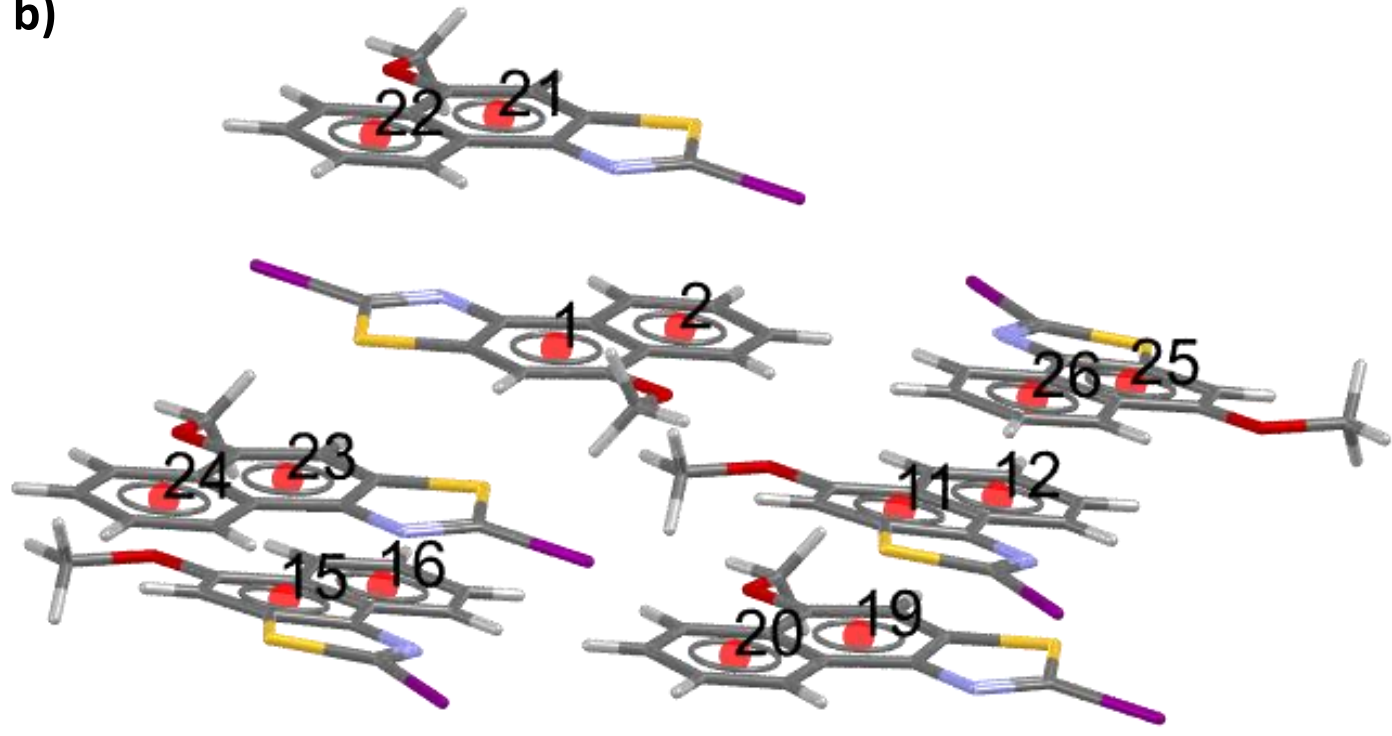

C)

\begin{tabular}{|c|c|c|c|c|}
\hline Centroid 1 & Centroid 2 & Distance & Score & Profile \\
\hline 1 & 21 & 3.75 & 10 & Strong \\
\hline 1 & 22 & 4.68 & 8 & Strong \\
\hline 2 & 21 & 4.68 & 8 & Strong \\
\hline 1 & 16 & 5.43 & 7.1 & Strong \\
\hline 2 & 11 & 5.43 & 7.1 & Strong \\
\hline 1 & 23 & 6.22 & 4 & Moderate \\
\hline
\end{tabular}




\begin{tabular}{|l|l|l|l|l|}
\hline 2 & 22 & 6.46 & 3.6 & Moderate \\
\hline 2 & 26 & 6.6 & 3.1 & Moderate \\
\hline 2 & 20 & 6.49 & 3.1 & Moderate \\
\hline
\end{tabular}

Figure S7: Role of aromatic ring stabilization in a) NTI full view, b) NTI close view and c) table showing strong and moderate aromatic interactions using aromatic analyzer component in Mercury 4.0.

a)

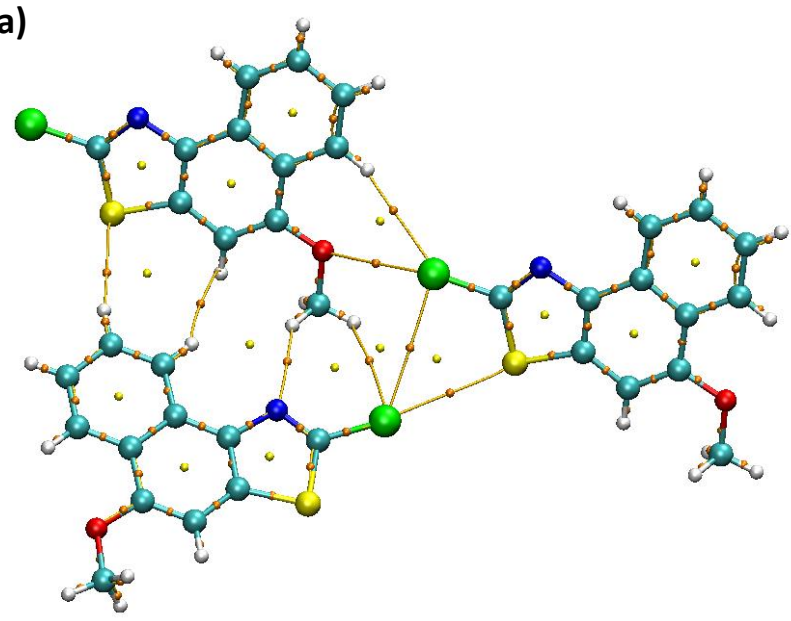

b)

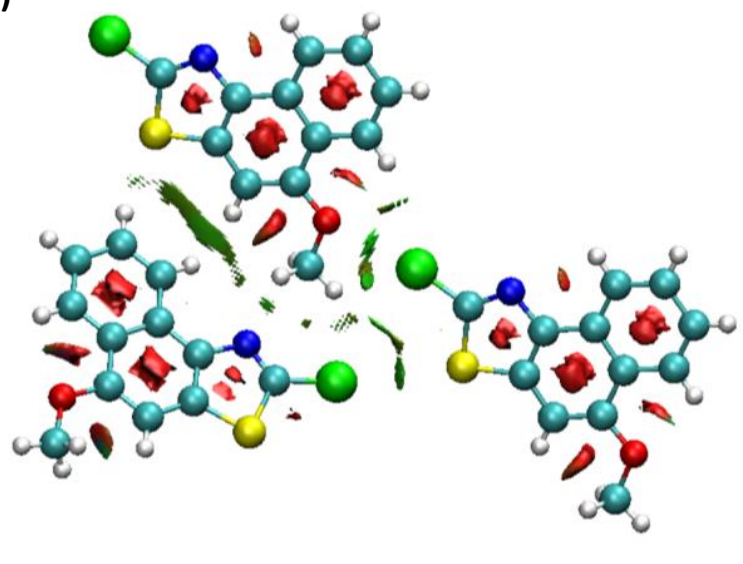

Figure S8: QTAIM electron density map and NCI plot showing weak stabilizing interactions in NTC.

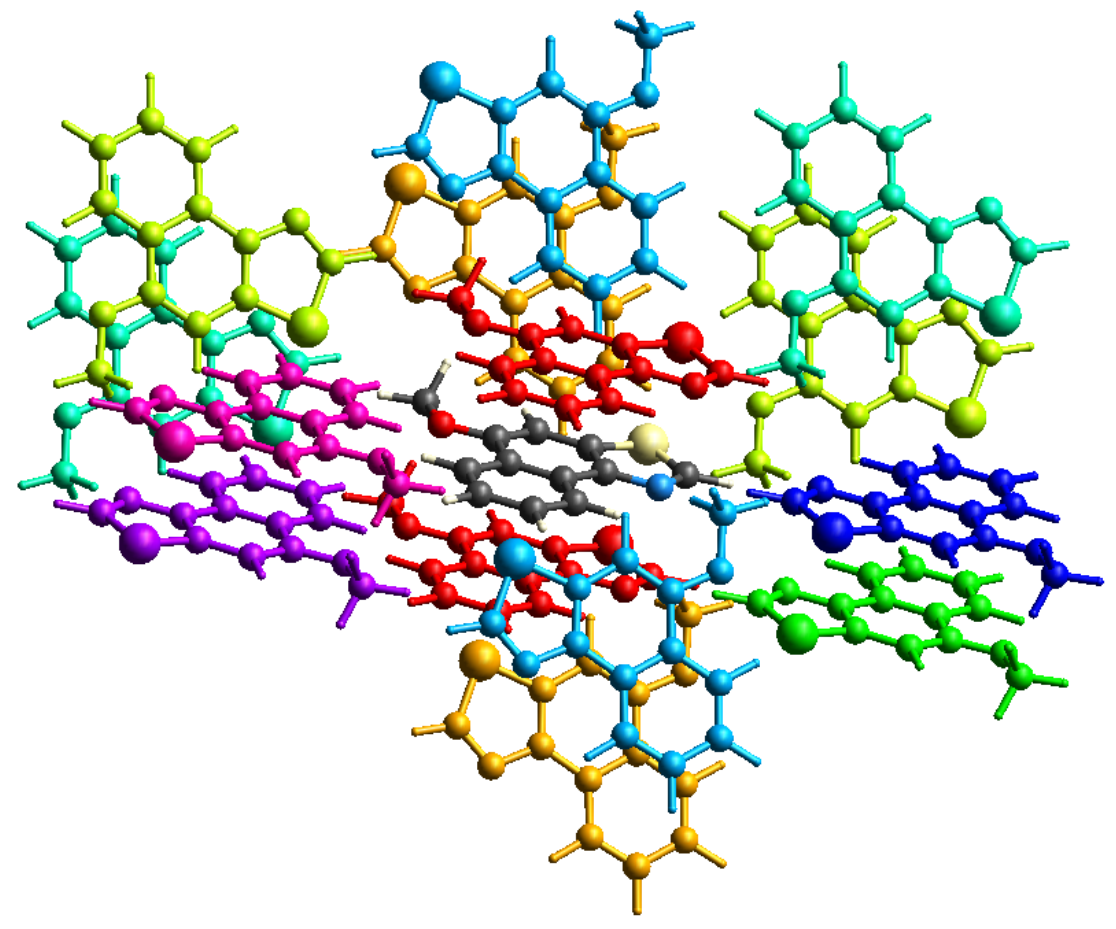


Interaction Energies ( $\mathrm{kJ} / \mathrm{mol}$ )

$\mathrm{R}$ is the distance between molecular centroids (mean atomic position) in $\mathrm{A}$.

Total energies, only reported for two benchmarked energy models, are the sum of the four energy components, scaled appropriately (see the scale factor table below)

\begin{tabular}{|r|l|r|l|r|r|r|r|r|}
\hline $\mathrm{N}$ & Symop & R & Electron Density & E_ele & E_pol & E_dis & E_rep & E_tot \\
\hline 1 & $\mathrm{x}, \mathrm{y}, \mathrm{z}$ & 4.07 & B3LYP/DGDZVP & -14.6 & -3.6 & -57.9 & 49.8 & -37.7 \\
\hline 0 & $-\mathrm{x}+1 / 2, \mathrm{y}+1 / 2,-\mathrm{z}+1 / 2$ & 7.35 & B3LYP/DGDZVP & -9.0 & -1.9 & -18.3 & 14.8 & -17.8 \\
\hline 1 & $\mathrm{x}+1 / 2,-\mathrm{y}+1 / 2, \mathrm{z}+1 / 2$ & 9.86 & B3LYP/DGDZVP & -1.4 & -0.4 & -6.2 & 7.0 & -2.9 \\
\hline 0 & $-\mathrm{x},-\mathrm{y},-\mathrm{z}$ & 9.40 & B3LYP/DGDZVP & -5.1 & -0.5 & -6.5 & 4.9 & -8.4 \\
\hline 1 & $\mathrm{x}+1 / 2,-\mathrm{y}+1 / 2, \mathrm{z}+1 / 2$ & 10.10 & B3LYP/DGDZVP & -1.0 & -0.5 & -6.2 & 6.4 & -2.9 \\
\hline 2 & $-\mathrm{x}+1 / 2, \mathrm{y}+1 / 2,-\mathrm{z}+1 / 2$ & 7.76 & B3LYP/DGDZVP & -4.4 & -0.7 & -13.7 & 11.4 & -10.0 \\
\hline 1 & $-\mathrm{x},-\mathrm{y},-\mathrm{z}$ & 9.10 & B3LYP/DGDZVP & -18.0 & -2.7 & -11.8 & 17.9 & -20.3 \\
\hline 0 & $-\mathrm{x},-\mathrm{y},-\mathrm{z}$ & 8.68 & B3LYP/DGDZVP & -5.3 & -0.6 & -16.1 & 11.4 & -13.0 \\
\hline 1 & $-\mathrm{x},-\mathrm{y},-\mathrm{z}$ & 9.66 & B3LYP/DGDZVP & -2.3 & -0.2 & -8.2 & 4.2 & -7.1 \\
\hline
\end{tabular}

Scale factors for benchmarked energy models See Mackenzie et al. IUCrJ (2017)

\begin{tabular}{|l|c|c|c|c|}
\hline Energy Model & k_ele & k_pol & k_disp & k_rep \\
\hline CE-HF ... HF/3-21G electron densities & 1.019 & 0.651 & 0.901 & 0.811 \\
\hline CE-B3LYP ... B3LYP/6-31G(d,p) electron densities & 1.057 & 0.740 & 0.871 & 0.618 \\
\hline
\end{tabular}

Figure S9: Intermolecular interaction energies of molecular pairs and interaction topologies of NTH.

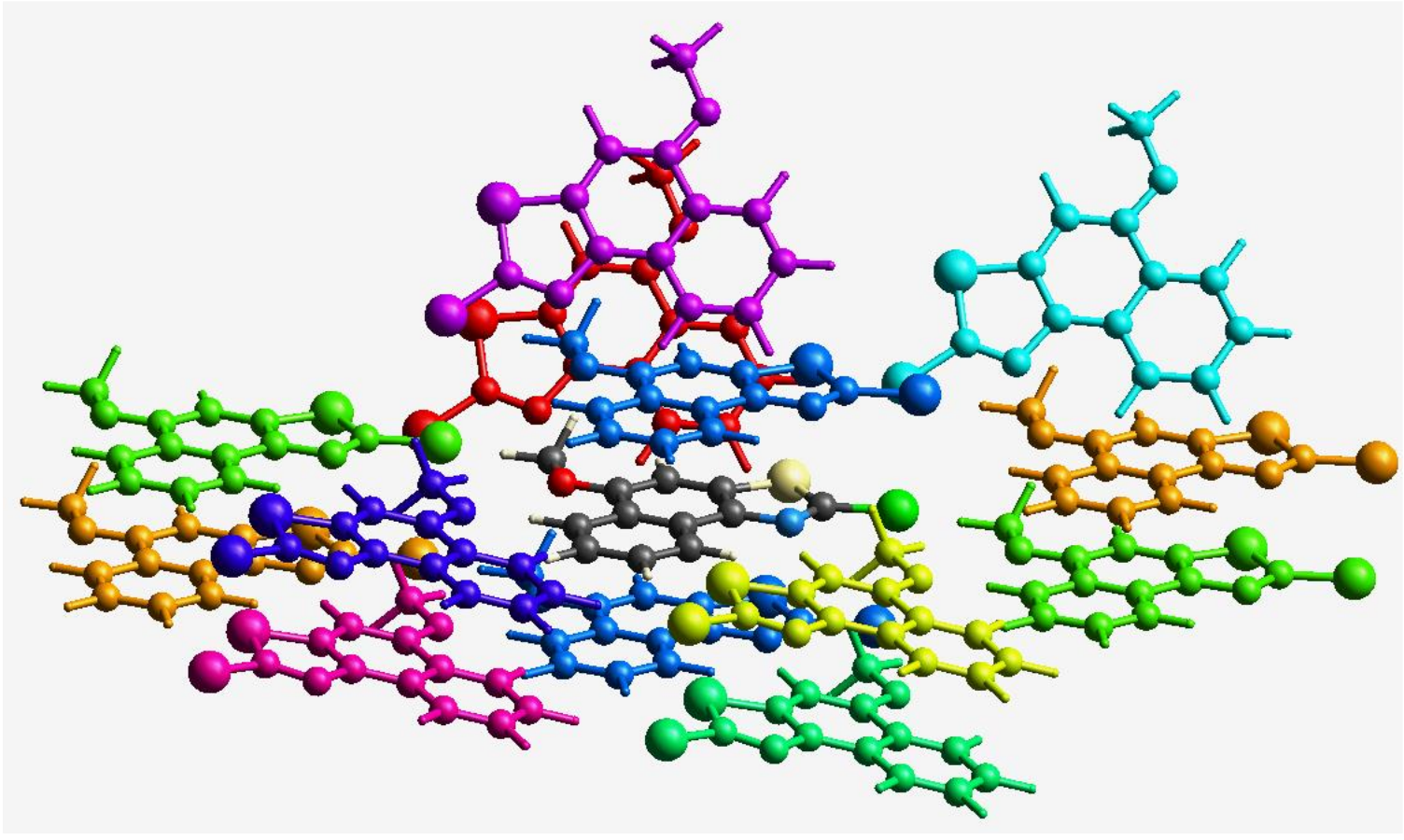


Interaction Energies ( $\mathrm{kJ} / \mathrm{mol})$

$\mathrm{R}$ is the distance between molecular centroids (mean atomic position) in $\mathrm{A}$.

Total energies, only reported for two benchmarked energy models, are the sum of the four energy components, scaled appropriately (see the scale factor table below)

\begin{tabular}{|r|l|r|l|r|r|r|r|r|}
\hline $\mathrm{N}$ & Symop & R & Electron Density & E_ele & E_pol & E_dis & E_rep & E_tot \\
\hline 1 & - & 7.46 & B3LYP/DGDZVP & -11.6 & -2.5 & -22.2 & 18.8 & -21.8 \\
\hline 2 & $\mathrm{x}, \mathrm{y}, \mathrm{z}$ & 11.22 & B3LYP/DGDZVP & -1.5 & -0.2 & -4.4 & 3.3 & -3.5 \\
\hline 1 & - & 8.22 & B3LYP/DGDZVP & -7.9 & -1.9 & -13.8 & 11.4 & -14.7 \\
\hline 2 & $\mathrm{x}, \mathrm{y}, \mathrm{z}$ & 10.52 & B3LYP/DGDZVP & -6.6 & -0.3 & -9.9 & 14.3 & -6.9 \\
\hline 1 & - & 7.16 & B3LYP/DGDZVP & -10.7 & -1.5 & -18.4 & 18.4 & -17.0 \\
\hline 1 & - & 10.08 & B3LYP/DGDZVP & -2.0 & -0.1 & -6.4 & 10.1 & -1.5 \\
\hline 2 & $\mathrm{x}, \mathrm{y}, \mathrm{z}$ & 3.91 & B3LYP/DGDZVP & -20.2 & -3.2 & -68.7 & 64.1 & -43.8 \\
\hline 1 & - & 10.75 & B3LYP/DGDZVP & -2.5 & -0.5 & -11.8 & 7.8 & -8.5 \\
\hline 1 & - & 7.40 & B3LYP/DGDZVP & -8.7 & -1.6 & -16.2 & 13.7 & -16.1 \\
\hline 1 & - & 9.97 & B3LYP/DGDZVP & -2.8 & -0.5 & -11.5 & 5.5 & -9.9 \\
\hline
\end{tabular}

Scale factors for benchmarked energy models See Mackenzie et al. IUCrJ (2017)

\begin{tabular}{|l|c|c|c|c|}
\hline Energy Model & k_ele & k_pol & k_disp & k_rep \\
\hline CE-HF ... HF/3-21G electron densities & 1.019 & 0.651 & 0.901 & 0.811 \\
\hline CE-B3LYP ... B3LYP/6-31G(d,p) electron densities & 1.057 & 0.740 & 0.871 & 0.618 \\
\hline
\end{tabular}

Figure S10: Intermolecular interaction energies of molecular pairs and interaction topologies of NTC.

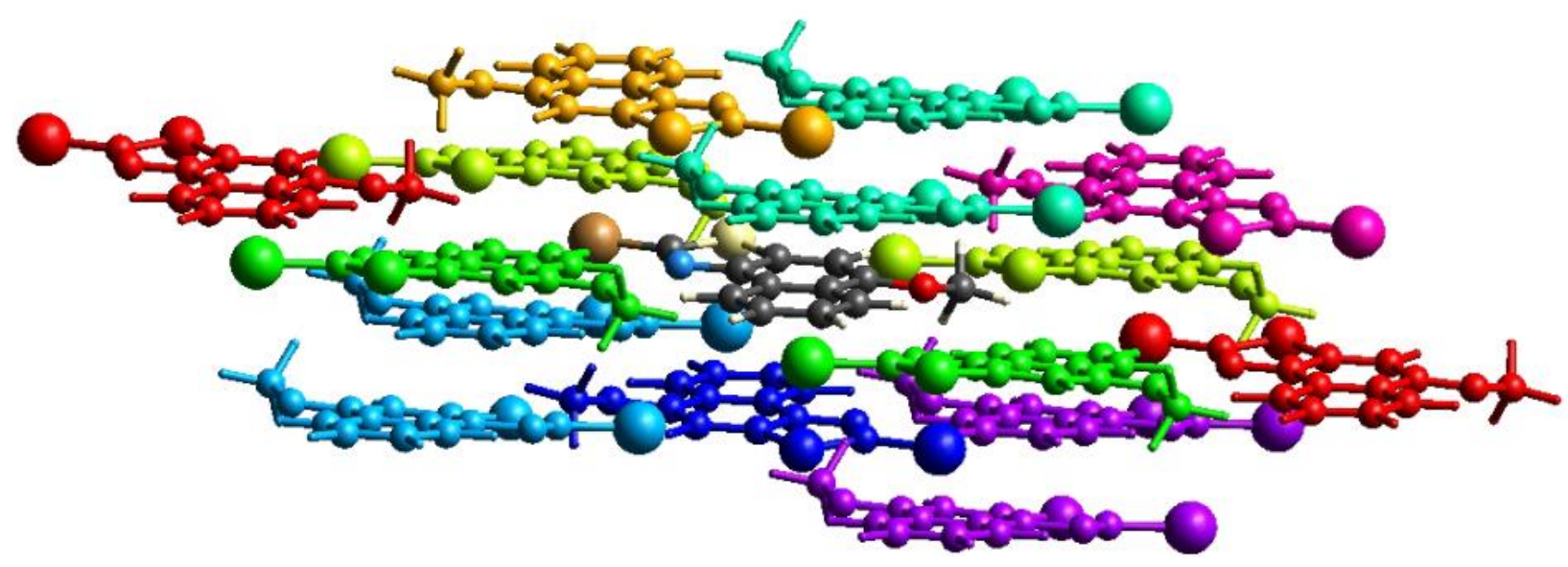


Interaction Energies $(\mathrm{kJ} / \mathrm{mol})$

$\mathrm{R}$ is the distance between molecular centroids (mean atomic position) in $\mathrm{A}$.

Total energies, only reported for two benchmarked energy models, are the sum of the four energy components, scaled appropriately (see the scale factor table below)

\begin{tabular}{|r|l|r|l|r|r|r|r|r|}
\hline $\mathrm{N}$ & Symop & R & Electron Density & E_ele & E_pol & E_dis & E_rep & $E_{-}$tot \\
\hline 2 & $\mathrm{x}, \mathrm{y}, \mathrm{z}$ & 12.68 & B3LYP/DGDZVP & 0.2 & -0.2 & -2.8 & 1.4 & -1.5 \\
\hline 1 & $-\mathrm{x},-\mathrm{y},-\mathrm{z}$ & 4.07 & B3LYP/DGDZVP & -18.9 & -1.7 & -52.7 & 48.5 & -37.2 \\
\hline 2 & $\mathrm{x}+1 / 2,-\mathrm{y}+1 / 2, \mathrm{z}+1 / 2$ & 9.09 & B3LYP/DGDZVP & -3.4 & -0.8 & -11.4 & 10.7 & -7.5 \\
\hline 2 & $\mathrm{x}+1 / 2,-\mathrm{y}+1 / 2, \mathrm{z}+1 / 2$ & 9.35 & B3LYP/DGDZVP & -6.8 & -1.5 & -16.9 & 15.7 & -13.4 \\
\hline 2 & $-\mathrm{x}+1 / 2, \mathrm{y}+1 / 2,-\mathrm{z}+1 / 2$ & 8.51 & B3LYP/DGDZVP & -10.2 & -1.2 & -17.6 & 15.1 & -17.6 \\
\hline 2 & $-\mathrm{x}+1 / 2, \mathrm{y}+1 / 2,-\mathrm{z}+1 / 2$ & 8.73 & B3LYP/DGDZVP & -3.5 & -0.2 & -7.5 & 6.9 & -6.1 \\
\hline 1 & $-\mathrm{x},-\mathrm{y},-\mathrm{z}$ & 3.69 & B3LYP/DGDZVP & -37.3 & -3.4 & -82.4 & 80.6 & -63.9 \\
\hline 2 & $-\mathrm{x}+1 / 2, \mathrm{y}+1 / 2,-\mathrm{z}+1 / 2$ & 11.00 & B3LYP/DGDZVP & -3.0 & -0.5 & -5.9 & 3.2 & -6.7 \\
\hline 1 & $-\mathrm{x},-\mathrm{y},-\mathrm{z}$ & 10.91 & B3LYP/DGDZVP & -6.6 & -1.2 & -15.7 & 8.8 & -16.1 \\
\hline
\end{tabular}

Scale factors for benchmarked energy models See Mackenzie et al. IUCrJ (2017)

\begin{tabular}{|l|c|c|c|c|}
\hline Energy Model & k_ele & k_pol & k_disp & k_rep \\
\hline CE-HF ... HF/3-21G electron densities & 1.019 & 0.651 & 0.901 & 0.811 \\
\hline CE-B3LYP ... B3LYP/6-31G(d,p) electron densities & 1.057 & 0.740 & 0.871 & 0.618 \\
\hline
\end{tabular}

Figure S11: Intermolecular interaction energies of molecular pairs and interaction topologies of NTB.

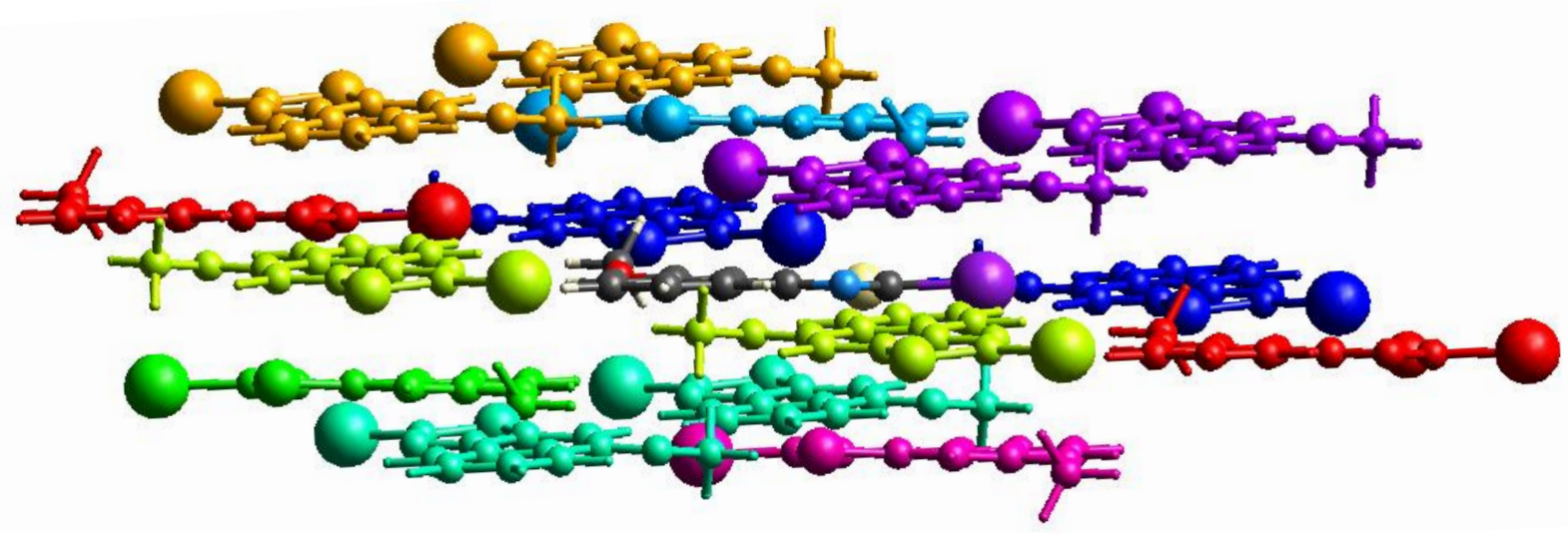


Interaction Energies ( $\mathrm{kJ} / \mathrm{mol})$

$\mathrm{R}$ is the distance between molecular centroids (mean atomic position) in $\mathbf{A}$.

Total energies, only reported for two benchmarked energy models, are the sum of the four energy components, scaled appropriately (see the scale factor table below)

\begin{tabular}{|r|l|r|l|r|r|r|r|r|}
\hline N & Symop & R & Electron Density & E_ele & E_pol & E_dis & E_rep & E_tot \\
\hline 2 & $\mathrm{x}, \mathrm{y}, \mathrm{z}$ & 12.87 & B3LYP/DGDZVP & 0.9 & -0.4 & -4.1 & 2.9 & -1.1 \\
\hline 2 & $-\mathrm{x}+1 / 2, y+1 / 2,-z+1 / 2$ & 11.90 & B3LYP/DGDZVP & -3.0 & -0.5 & -5.5 & 2.7 & -6.6 \\
\hline 2 & $\mathrm{x}+1 / 2,-\mathrm{y}+1 / 2, z+1 / 2$ & 9.66 & B3LYP/DGDZVP & -7.1 & -1.5 & -17.7 & 16.2 & -14.0 \\
\hline 1 & $-\mathrm{x},-\mathrm{y},-\mathrm{z}$ & 12.08 & B3LYP/DGDZVP & -6.0 & -1.1 & -15.2 & 7.7 & -15.7 \\
\hline 2 & $-\mathrm{x}+1 / 2, y+1 / 2,-z+1 / 2$ & 9.15 & B3LYP/DGDZVP & -10.1 & -1.3 & -17.6 & 14.9 & -17.7 \\
\hline 1 & $-\mathrm{x},-\mathrm{y},-\mathrm{z}$ & 4.29 & B3LYP/DGDZVP & -38.8 & -3.3 & -85.9 & 84.9 & -65.9 \\
\hline 2 & $\mathrm{x}+1 / 2,-\mathrm{y}+1 / 2, z+1 / 2$ & 8.97 & B3LYP/DGDZVP & -4.7 & -0.9 & -13.3 & 13.0 & -9.2 \\
\hline 2 & $-\mathrm{x}+1 / 2, y+1 / 2,-z+1 / 2$ & 8.24 & B3LYP/DGDZVP & -5.4 & -0.3 & -10.1 & 12.5 & -6.9 \\
\hline 1 & $-x,-y,-z$ & 3.78 & B3LYP/DGDZVP & -26.8 & -1.9 & -60.4 & 64.9 & -42.2 \\
\hline
\end{tabular}

Scale factors for benchmarked energy models See Mackenzie et al. IUCrJ (2017)

\begin{tabular}{|l|c|c|c|c|}
\hline Energy Model & k_ele & k_pol & k_disp & k_rep \\
\hline CE-HF ... HF/3-21G electron densities & 1.019 & 0.651 & 0.901 & 0.811 \\
\hline CE-B3LYP ... B3LYP/6-31C(d,p) electron densities & 1.057 & 0.740 & 0.871 & 0.618 \\
\hline
\end{tabular}

Figure S12: Intermolecular interaction energies of molecular pairs and interaction topologies of NTI.

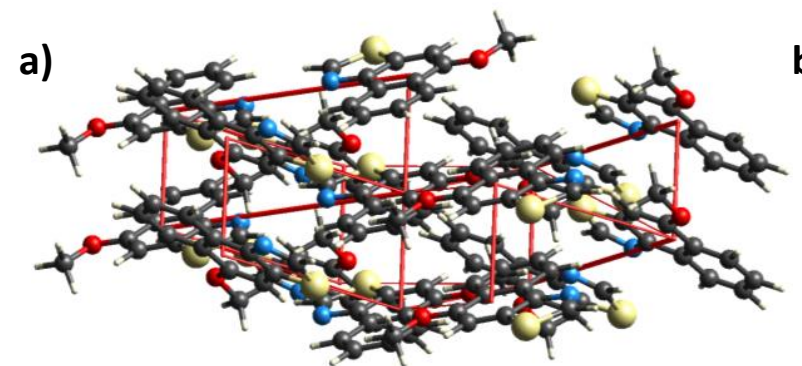

b)
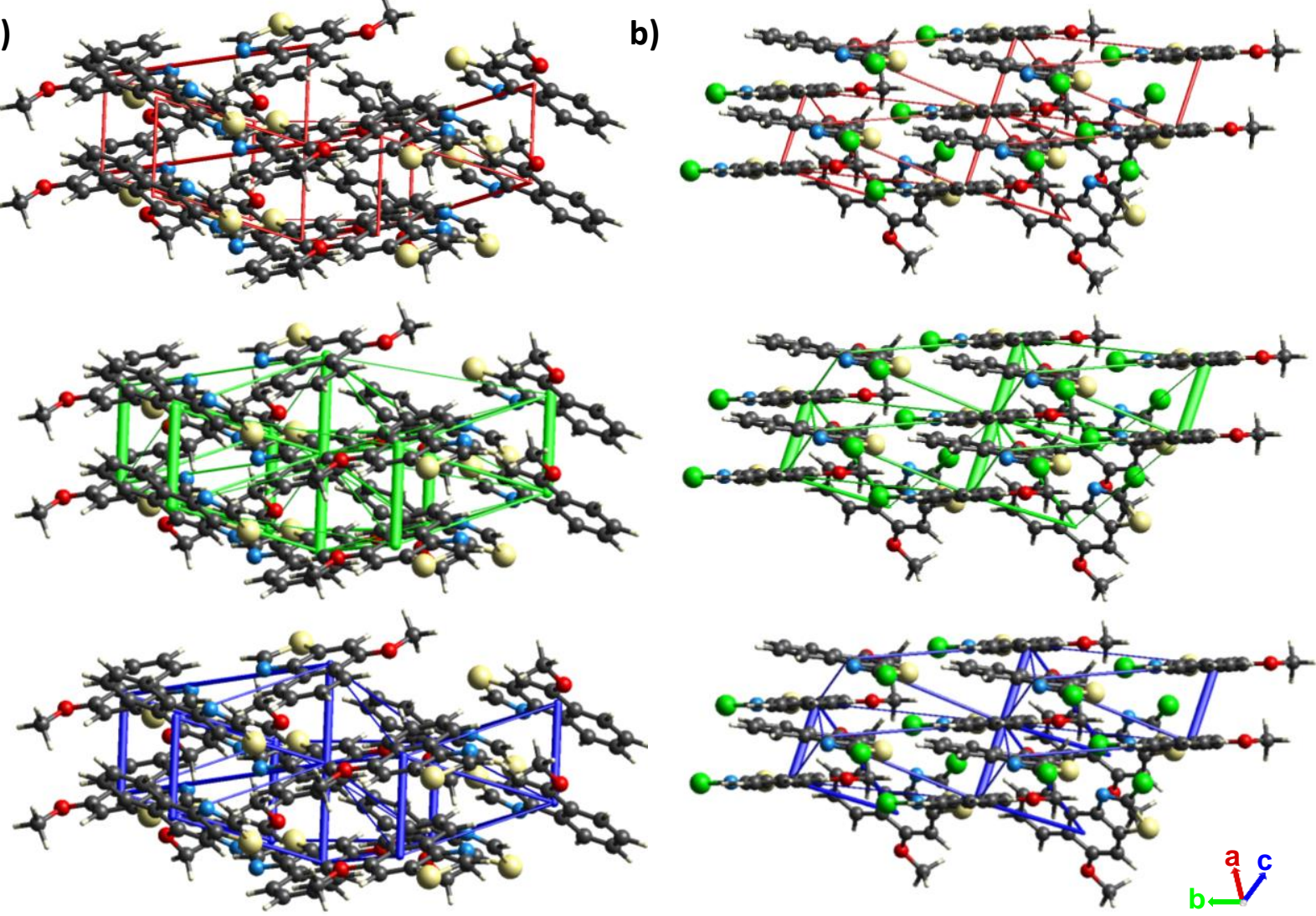

Figure S13: Energy framework for separate electrostatic (red), dispersion (green) and total energy (blue) for a) NT and b) NTC. The energy scale factor is 50 and the energy threshold is $5 \mathrm{~kJ} / \mathrm{mol}^{-1}$. 

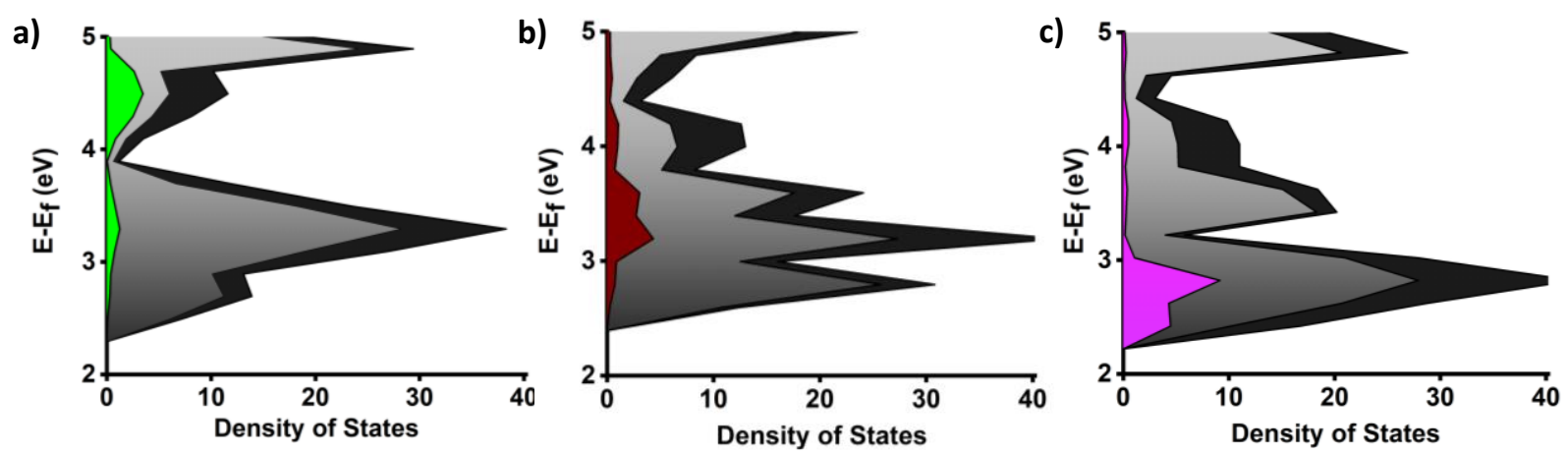

Figure S14: Close view of conduction bands from projected density of states (states/eV) of (a) NTC, (b) NTB and (c) NTI.
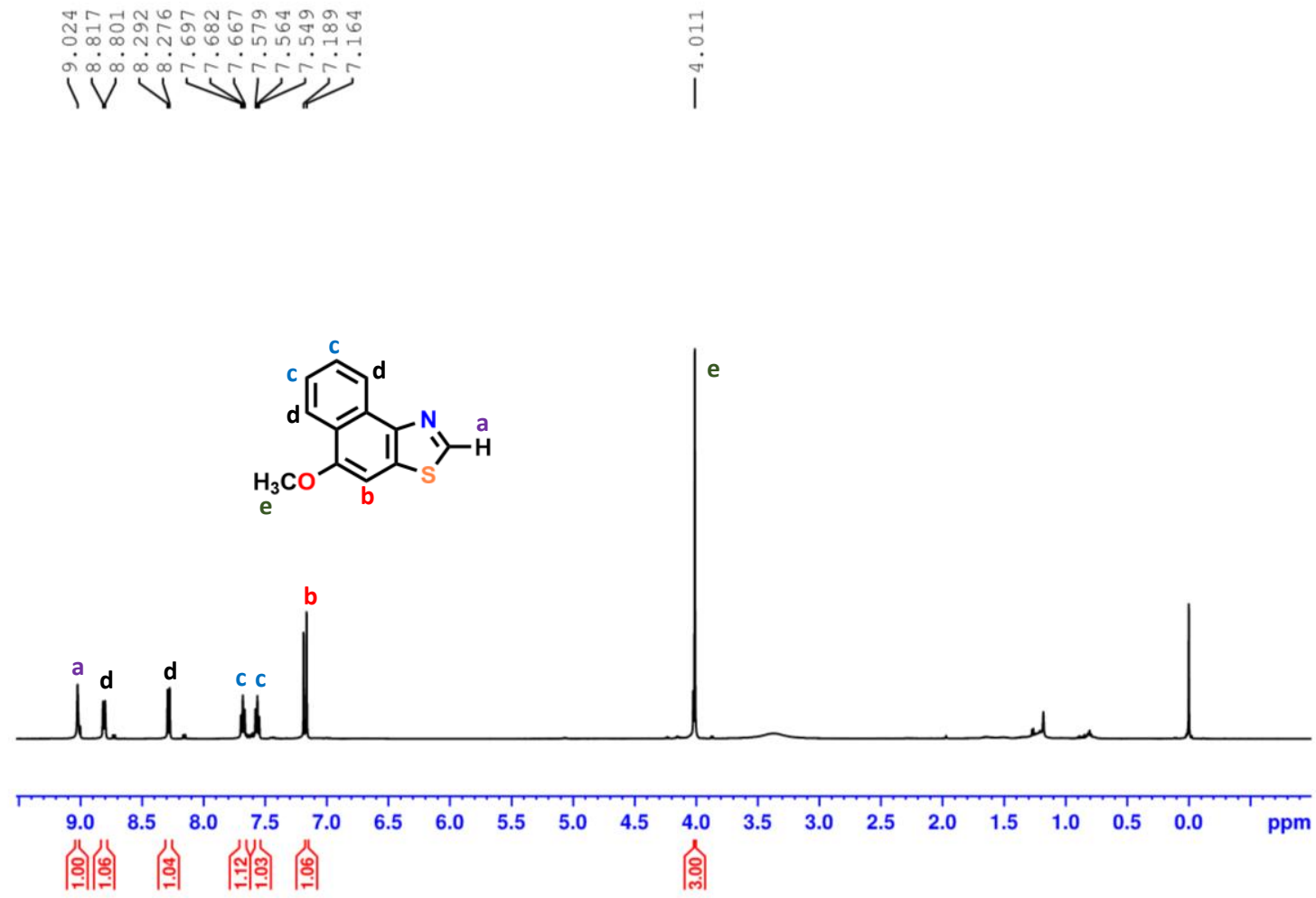

Figure S15: ${ }^{1} \mathrm{H}$ NMR spectrum of 5-methoxynaphtho[1,2-d] thiazole in $\mathrm{CDCl}_{3}$ 


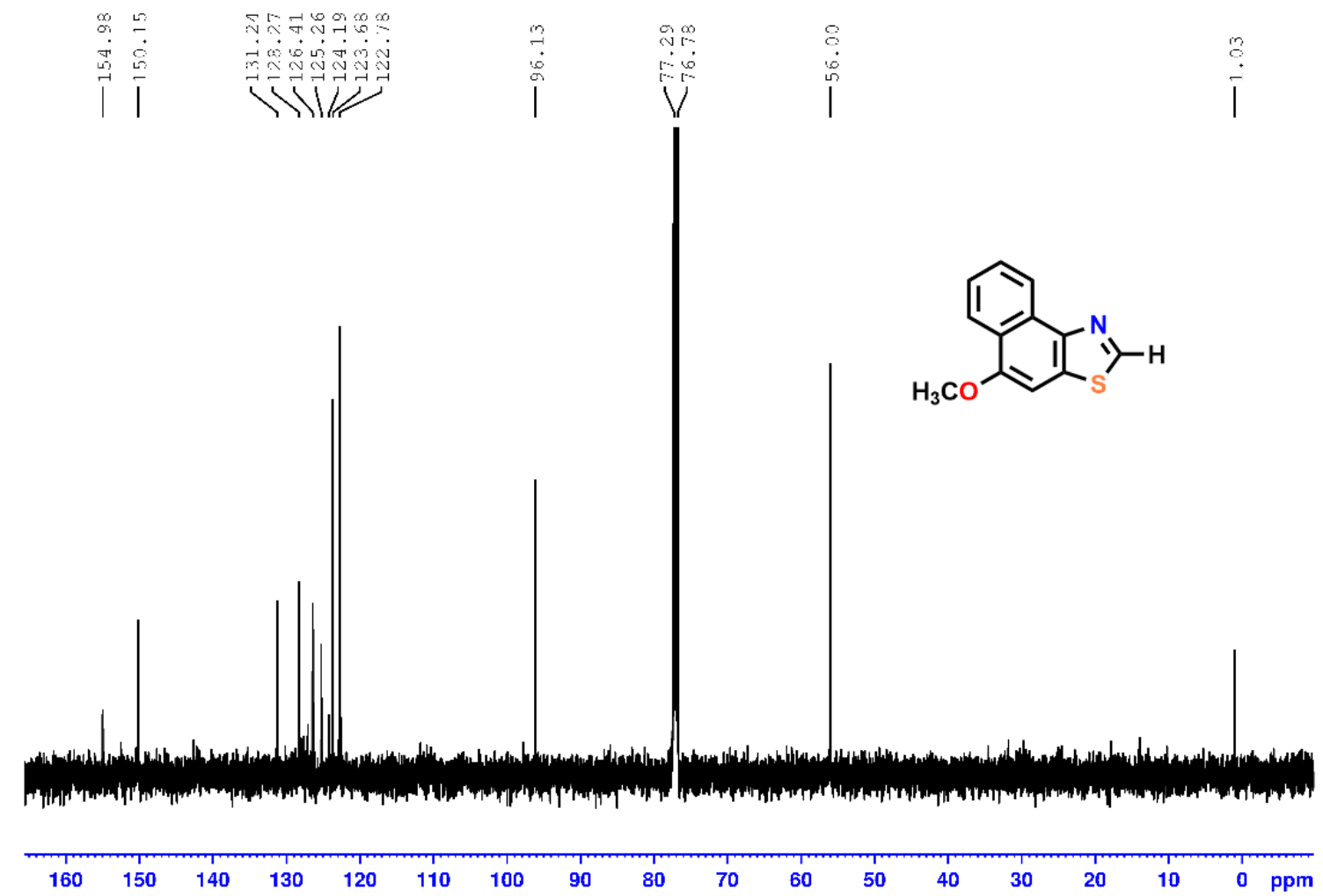

Figure S16: ${ }^{13} \mathrm{C}$ NMR spectrum of 5-methoxynaphtho[1,2- $d$ ] thiazole in $\mathrm{CDCl}_{3}$

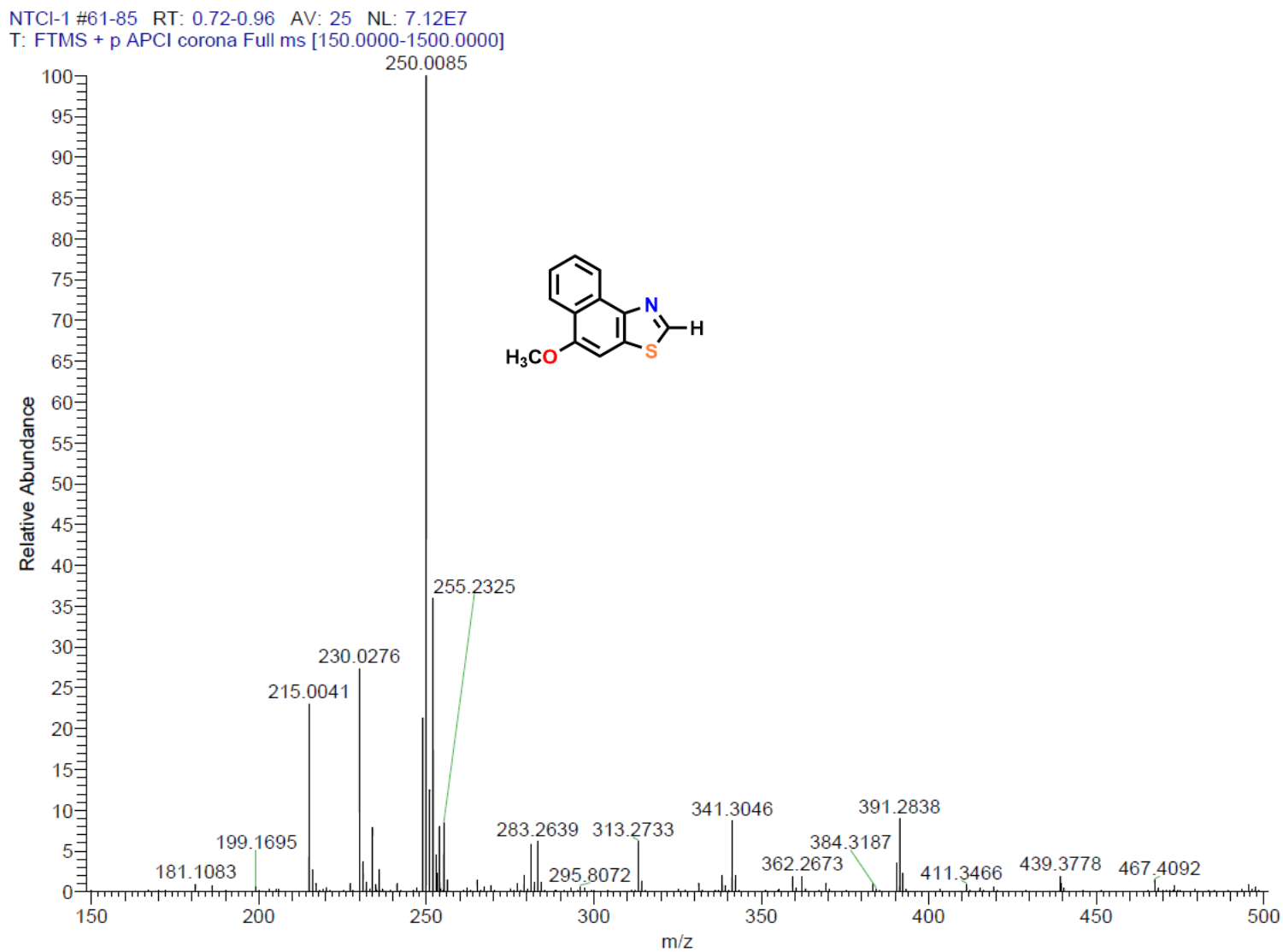

Figure S17: HRMS spectrum of 5-methoxynaphtho[1,2-d]thiazole 


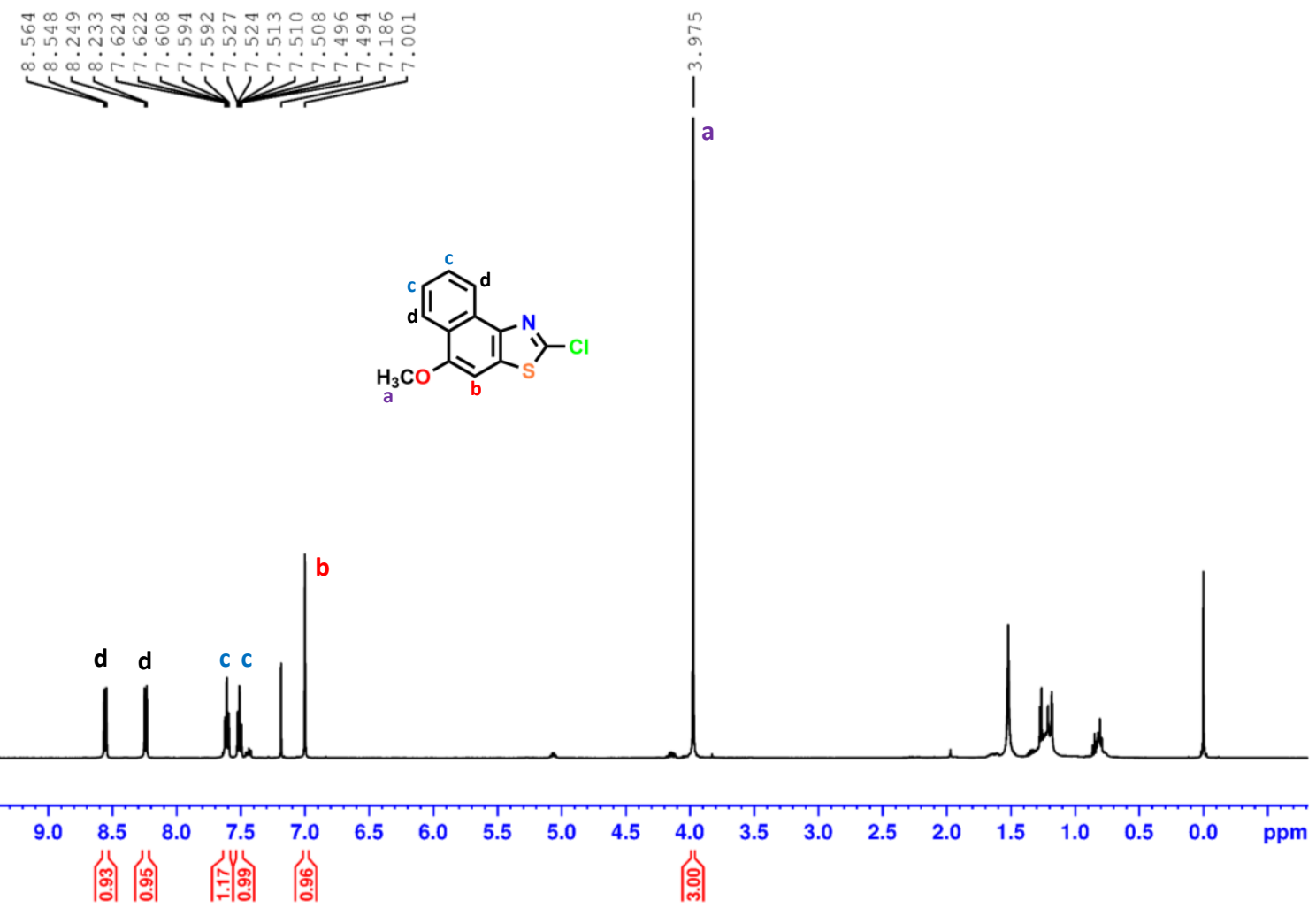

Figure S18: ${ }^{1} \mathrm{H}$ NMR spectrum of 2-chloro-5-methoxynaphtho[1,2-d] thiazole in $\mathrm{CDCl}_{3}$

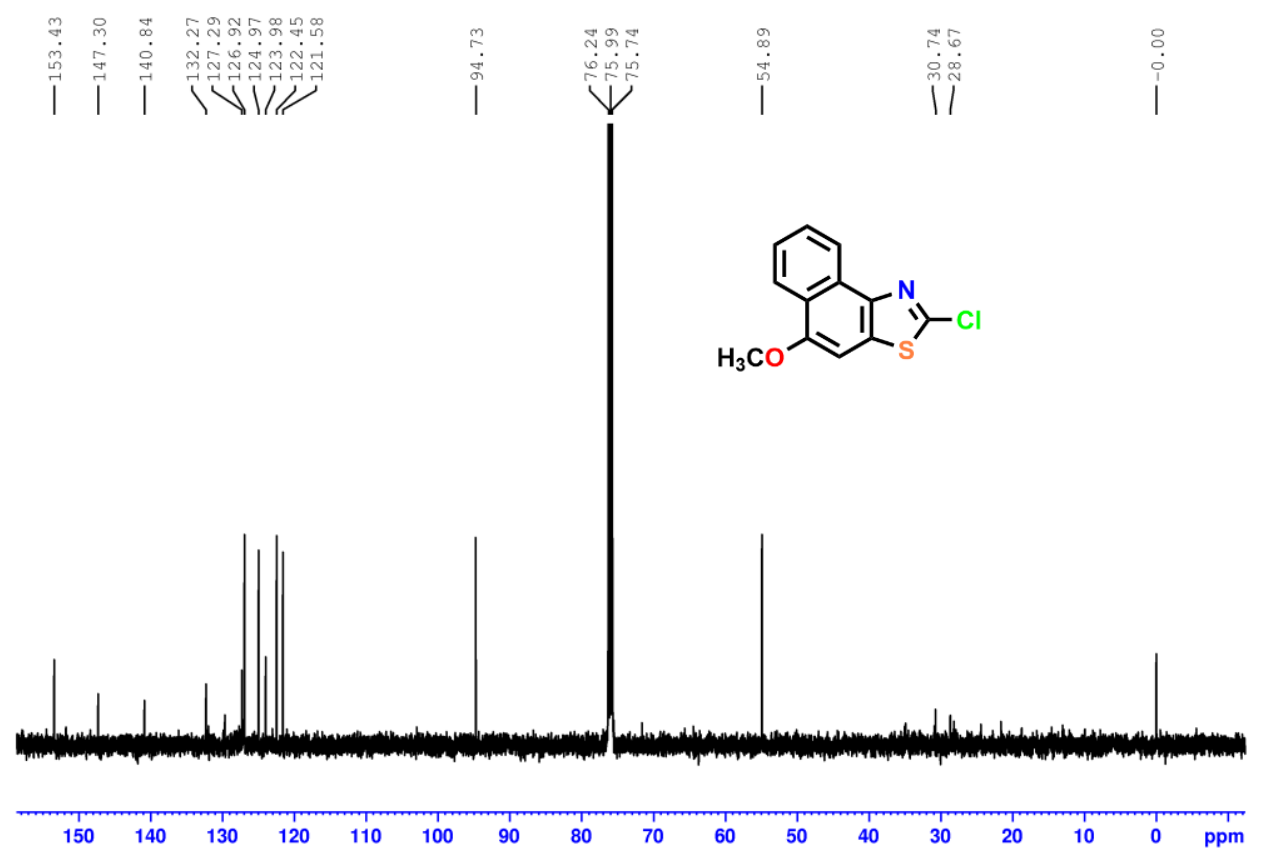

Figure S19: ${ }^{13} \mathrm{C}$ NMR spectrum of 2-chloro-5-methoxynaphtho[1,2-d] thiazole in $\mathrm{CDCl}_{3}$ 


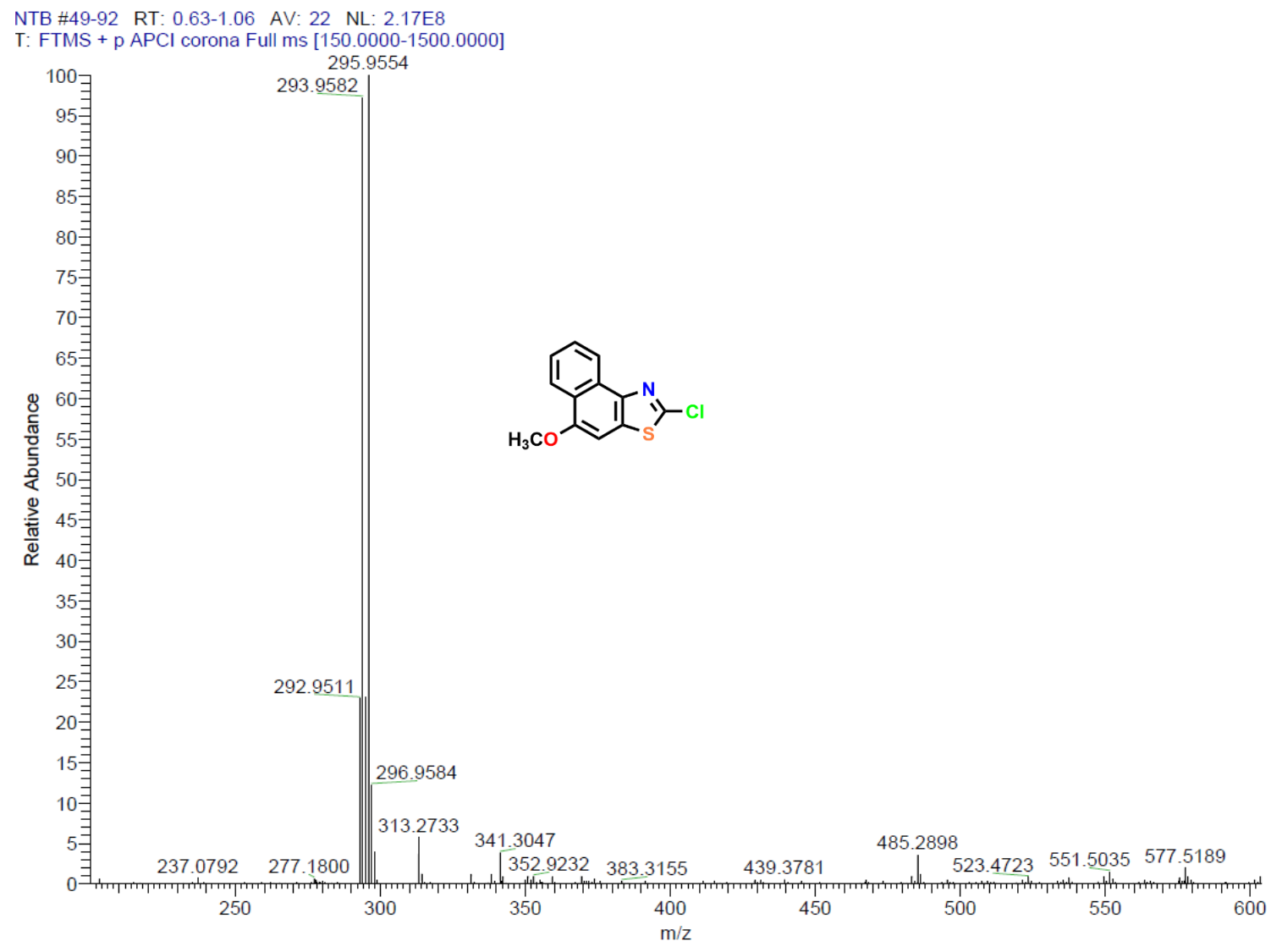

Figure S20: HRMS spectrum of 2-chloro-5-methoxynaphtho[1,2-d]thiazole
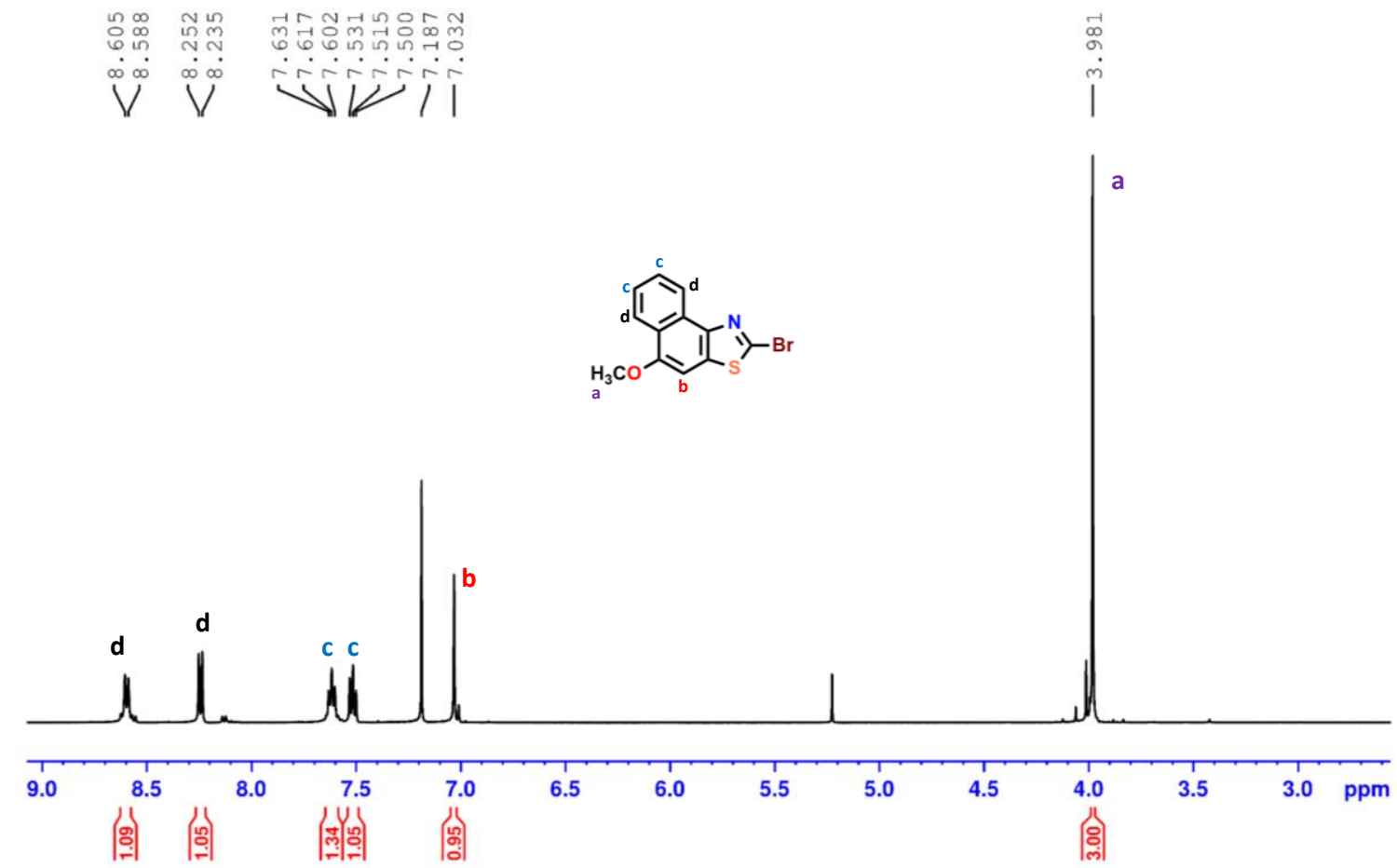

$\sqrt{3}$

Figure S21: ${ }^{1} \mathrm{H}$ NMR spectrum of 2-bromo-5-methoxynaphtho[1,2-d] thiazole in $\mathrm{CDCl}_{3}$ 


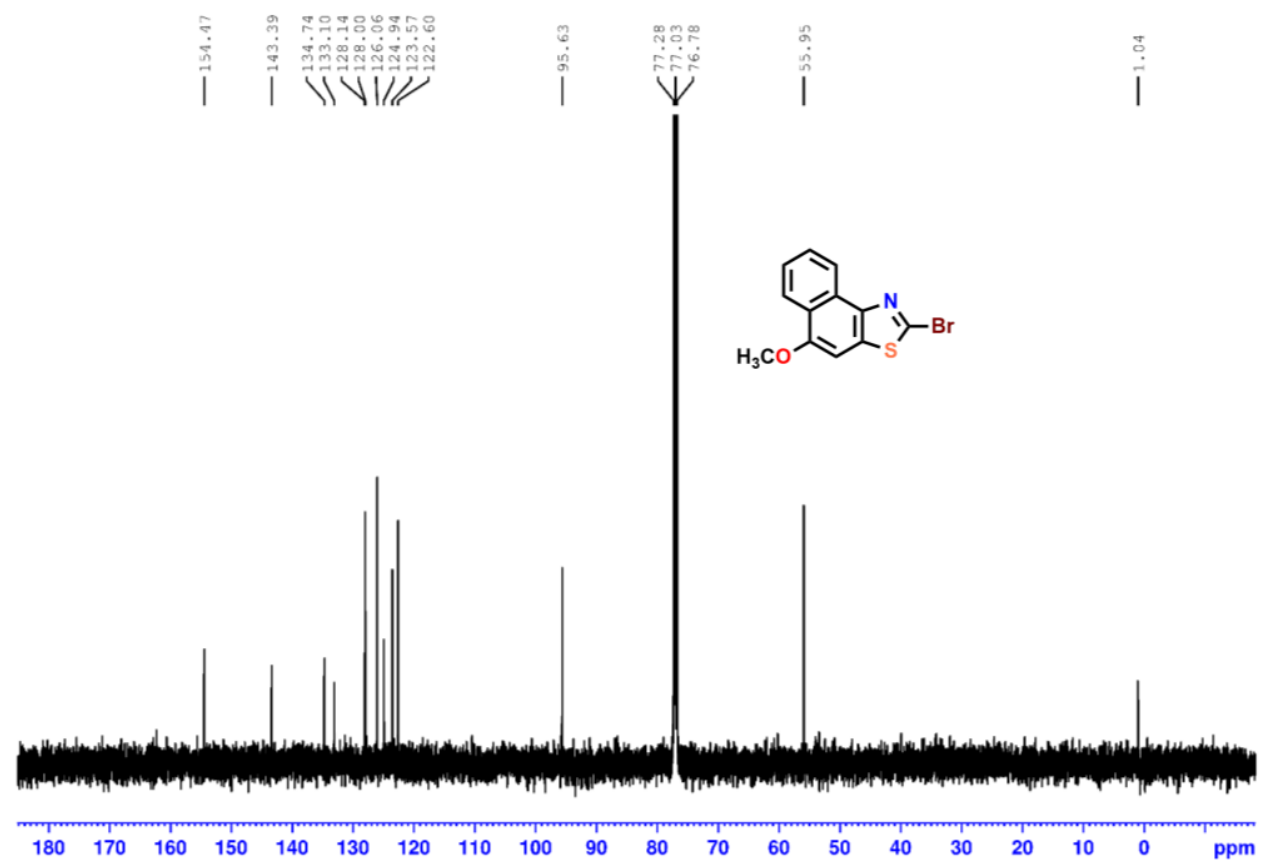

Figure S22: ${ }^{13} \mathrm{C}$ NMR spectrum of 2-bromo-5-methoxynaphtho[1,2-d] thiazole in $\mathrm{CDCl}_{3}$

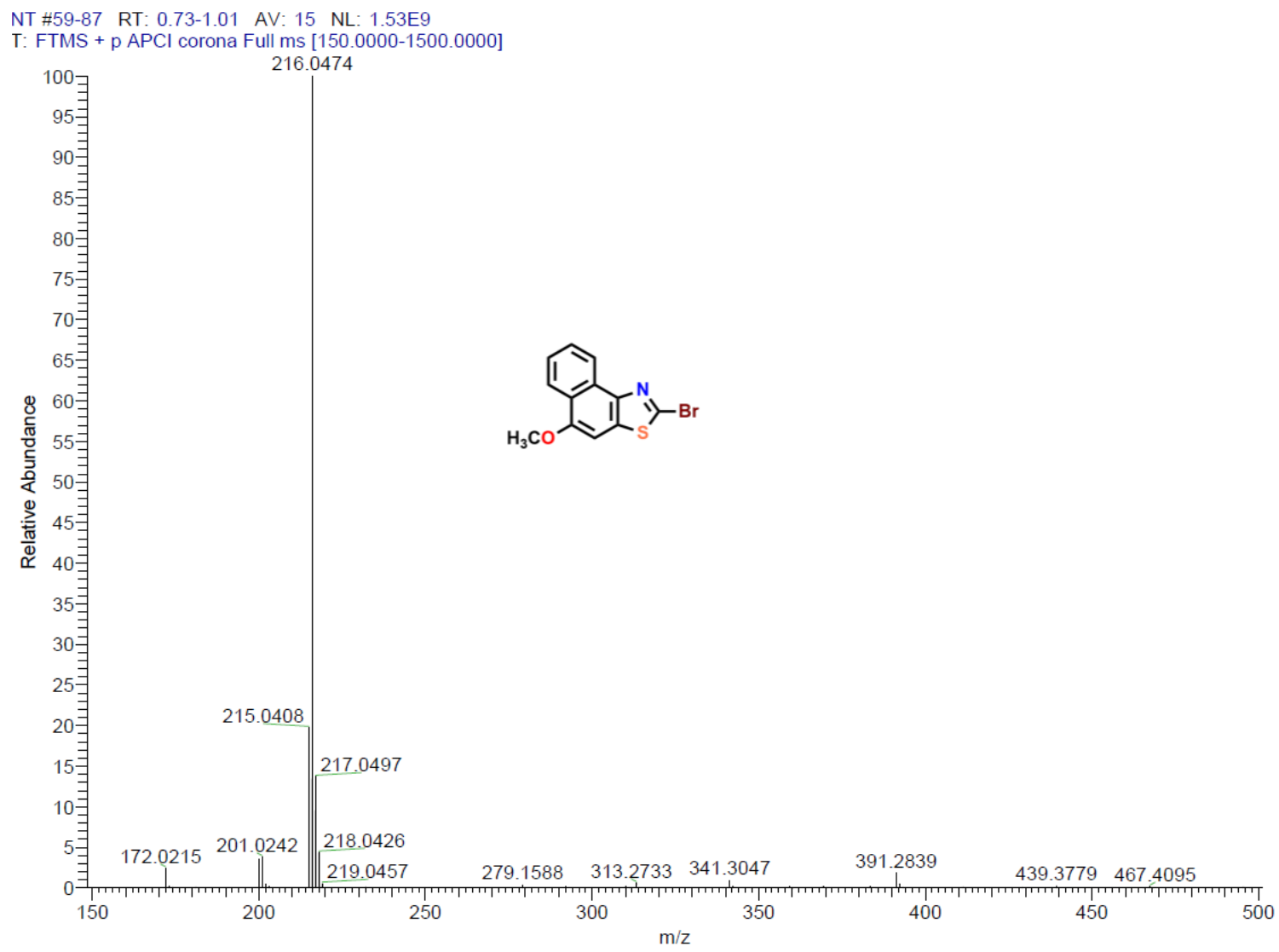

Figure S23: HRMS spectrum of 2-bromo-5-methoxynaphtho[1,2- $d]$ thiazole 


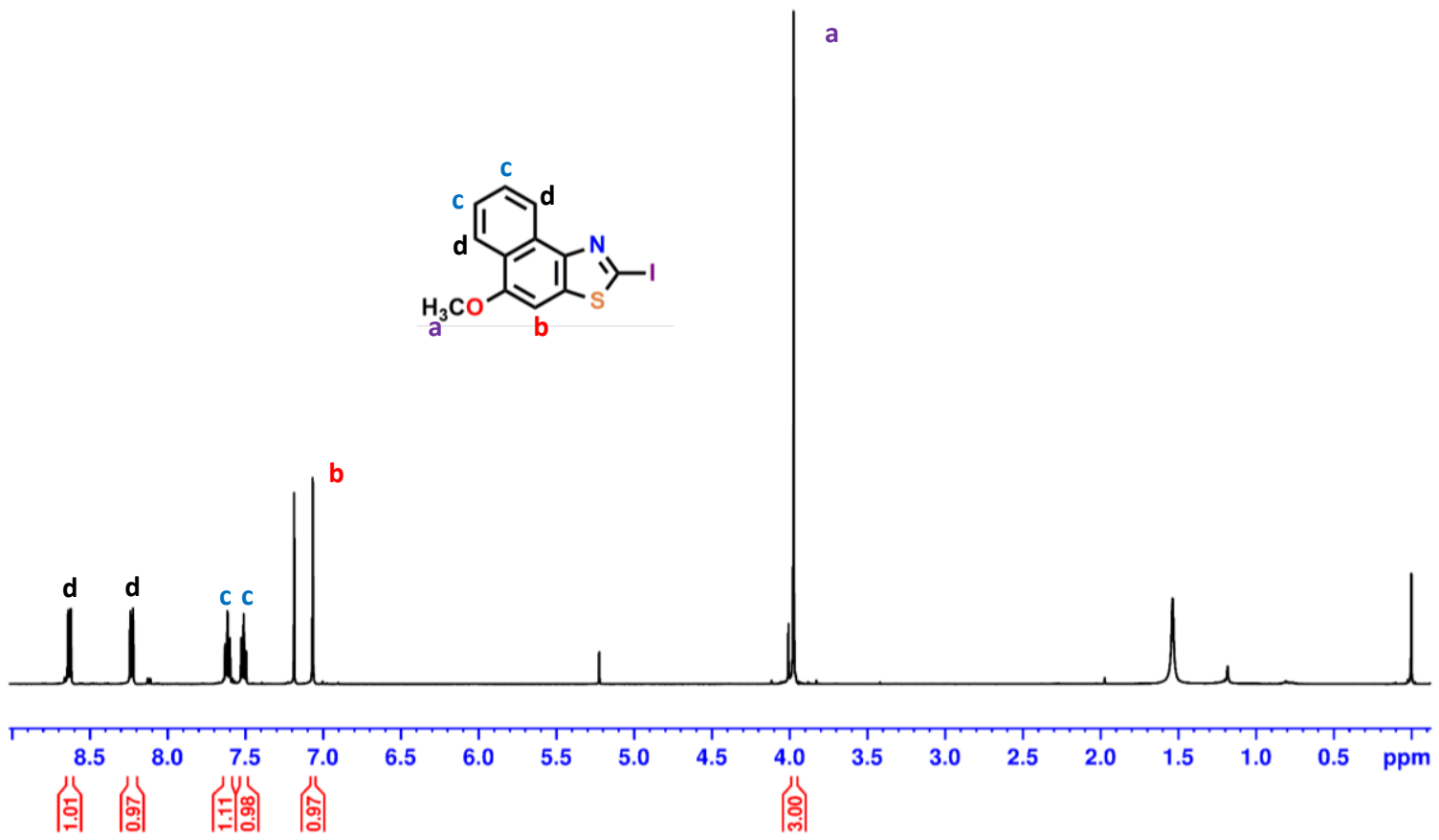

Figure S24: ${ }^{1} \mathrm{H}$ NMR spectrum of 2-iodo-5-methoxynaphtho[1,2-d] thiazole in $\mathrm{CDCl}_{3}$

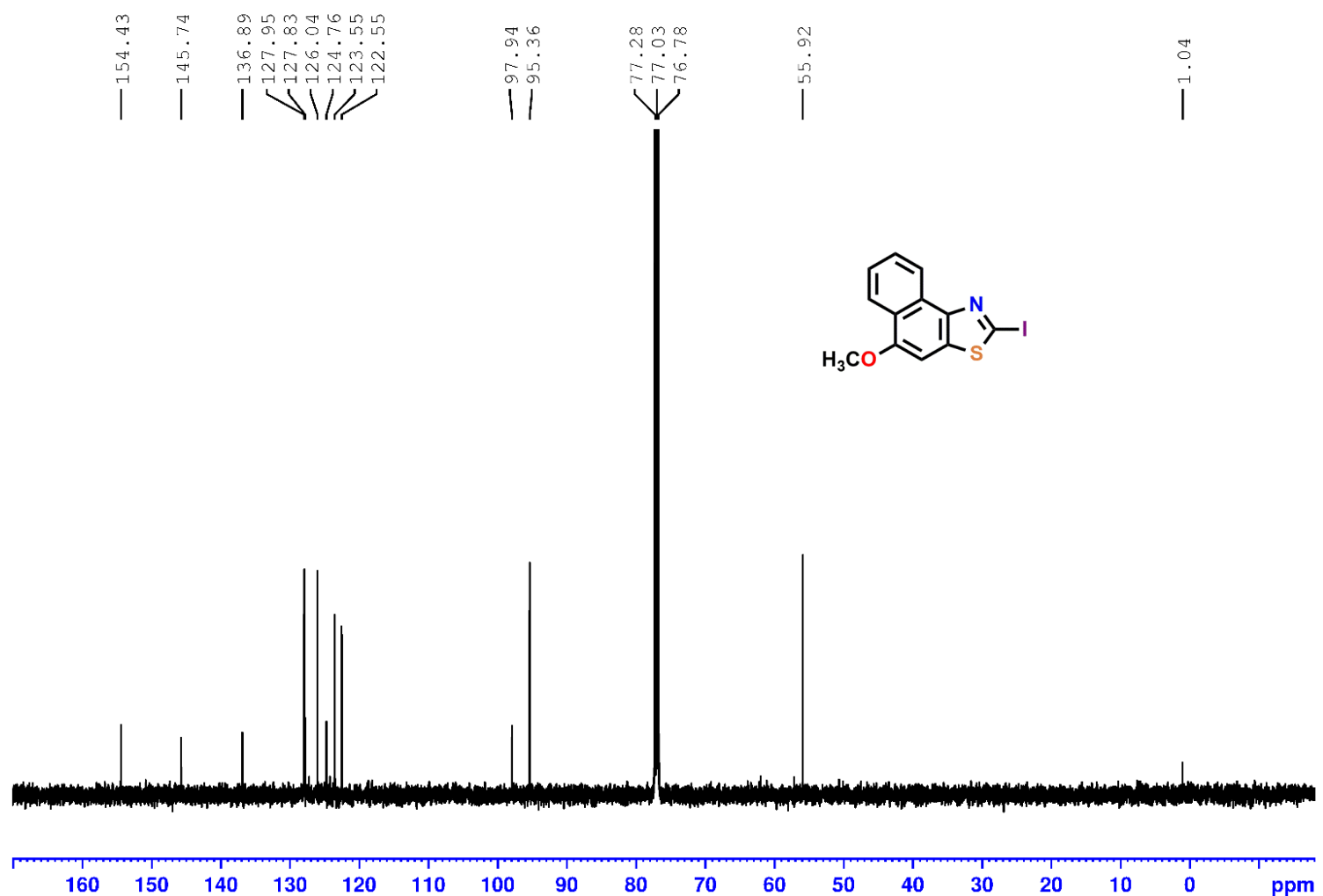

Figure S25: ${ }^{13} \mathrm{C}$ NMR spectrum of 2-iodo-5-methoxynaphtho[1,2- $\left.d\right]$ thiazole in $\mathrm{CDCl}_{3}$ 


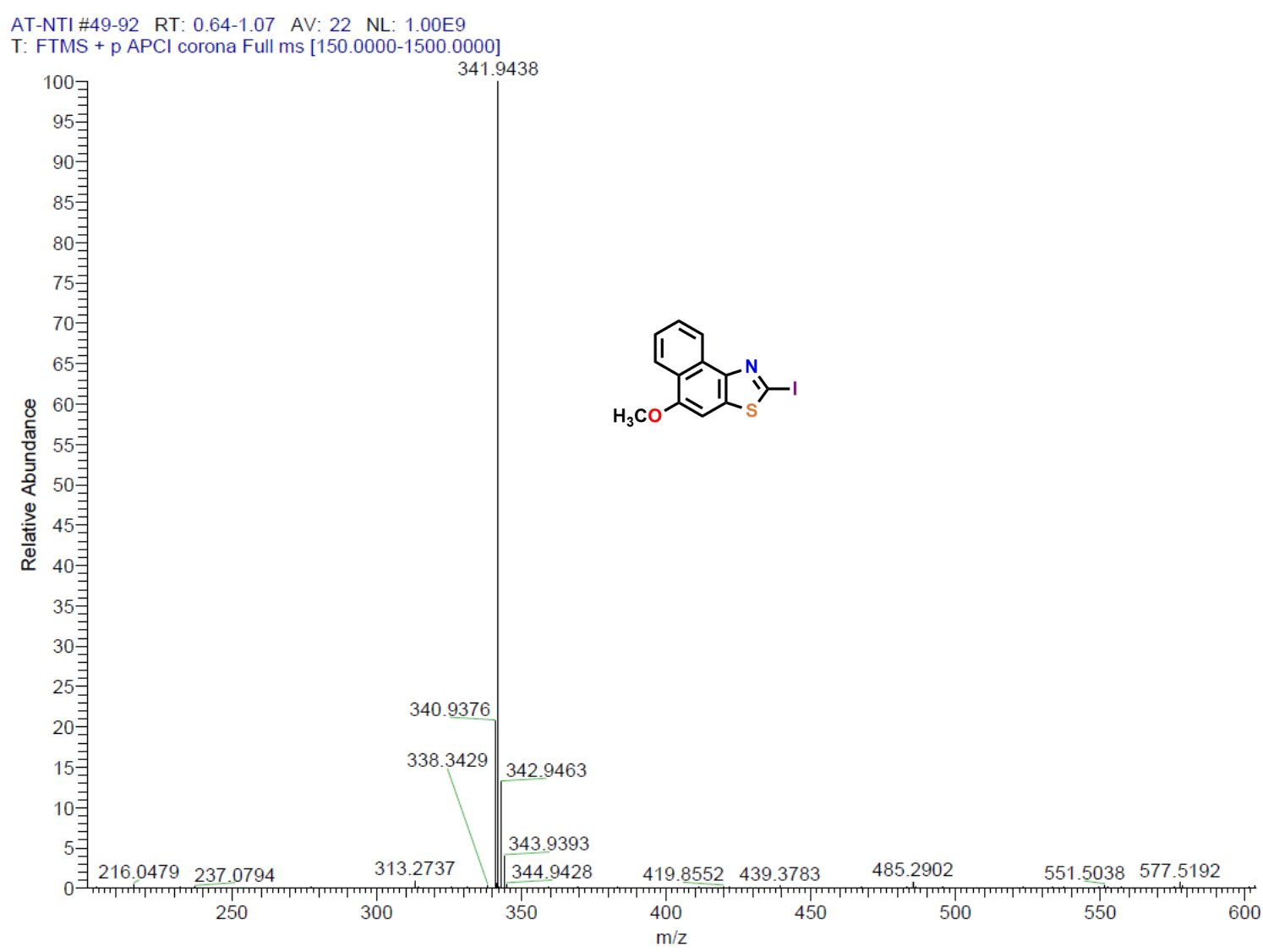

Figure S26: HRMS spectrum of 2-iodo-5-methoxynaphtho[1,2-d]thiazole

\section{Author Contributions}

† These authors contributed equally

\section{References:}

(1) Zhang, Y.; Sun, J.; Zhuang, G.; Ouyang, M.; Yu, Z.; Cao, F.; Pan, G.; Tang, P.; Zhang, C.; Ma, Y. Heating and Mechanical Force-Induced Luminescence on-off Switching of Arylamine Derivatives with Highly Distorted Structures. J. Mater. Chem. C 2014, 2, 195-200.

(2) Sheldrick, G. M. Crystal Structure Refinement with SHELXL. Acta Crystallogr. Sect. C Struct. Chem. 2015, $71,3-8$.

(3) Farrugia, L. J. WinGX Suite for Small-Molecule Single-Crystal Crystallography. J. Appl. Crystallogr. 1999, 32, 837-838.

(4) Macrae, C. F.; Sovago, I.; Cottrell, S. J.; Galek, P. T. A.; McCabe, P.; Pidcock, E.; Platings, M.; Shields, G. P.; Stevens, J. S.; Towler, M.; Wood, P. A. Mercury 4.0 : From Visualization to Analysis, Design and Prediction. J. Appl. Crystallogr. 2020, 53, 226-235.

(5) Kozuch, S.; Martin, J. M. L. Halogen Bonds: Benchmarks and Theoretical Analysis. J. Chem. Theory Comput. 2013, 9, 1918-1931.

(6) Frisch, M. J.; Trucks, G. W.; Schlegel, H. B.; Scuseria, G. E.; Robb, M. a.; Cheeseman, J. R.; Scalmani, G.; Barone, V.; Petersson, G. a.; Nakatsuji, H.; Li, X.; Caricato, M.; Marenich, a. V.; Bloino, J.; Janesko, B. G.; Gomperts, R.; Mennucci, B.; Hratchian, H. P.; Ortiz, J. V.; Izmaylov, a. F.; Sonnenberg, J. L.; Williams; Ding, F.; Lipparini, F.; Egidi, F.; Goings, J.; Peng, B.; Petrone, A.; Henderson, T.; Ranasinghe, D.; Zakrzewski, V. G.; Gao, J.; Rega, N.; Zheng, G.; Liang, W.; Hada, M.; Ehara, M.; Toyota, K.; Fukuda, R.; Hasegawa, J.; Ishida, M.; Nakajima, T.; Honda, Y.; Kitao, O.; Nakai, H.; Vreven, T.; Throssell, K.; Montgomery Jr., J. a.; Peralta, J. E.; Ogliaro, F.; Bearpark, M. J.; Heyd, J. J.; Brothers, E. N.; Kudin, K. N.; Staroverov, V. N.; Keith, T. a.; Kobayashi, R.; Normand, J.; Raghavachari, K.; Rendell, a. P.; Burant, J. C.; Iyengar, S. S.; Tomasi, J.; Cossi, M.; Millam, J. M.; Klene, M.; Adamo, C.; Cammi, R.; Ochterski, J. W.; Martin, R. L.; Morokuma, K.; Farkas, O.; Foresman, J. B.; Fox, D. J. G16_C01. 2016, p Gaussian 16, Revision C.01, Gaussian, Inc., Wallin.

(7) Bader, R. F. W. A Quantum Theory of Molecular Structure and Its Applications.

(8) Spackman, M. A.; Jayatilaka, D. Hirshfeld Surface Analysis. CrystEngComm 2009, 11, 19-32. 
(9) Spackman, P. R.; Turner, M. J.; McKinnon, J. J.; Wolff, S. K.; Grimwood, D. J.; Jayatilaka, D.; Spackman, M. A. CrystalExplorer: A Program for Hirshfeld Surface Analysis, Visualization and Quantitative Analysis of Molecular Crystals. J. Appl. Crystallogr. 2021, 54, 1006-1011.

(10) Turner, M. J.; Grabowsky, S.; Jayatilaka, D.; Spackman, M. A. Accurate and Efficient Model Energies for Exploring Intermolecular Interactions in Molecular Crystals. J. Phys. Chem. Lett. 2014, 5, 4249-4255.

(11) Contreras-García, J.; Johnson, E. R.; Keinan, S.; Chaudret, R.; Piquemal, J.-P.; Beratan, D. N.; Yang, W. NCIPLOT: A Program for Plotting Noncovalent Interaction Regions. J. Chem. Theory Comput. 2011, 7, 625632.

(12) Blanco, M. A.; Martín Pendás, A.; Francisco, E. Interacting Quantum Atoms: A Correlated Energy Decomposition Scheme Based on the Quantum Theory of Atoms in Molecules. J. Chem. Theory Comput. 2005, 1, 1096-1109. 